\title{
Iconographie professionnelle et féminisation du travail policier à New York (1945-1980)
}

"The Fairest of the Finest" : Institutional iconography and the feminization of the NYPD (1945-1980)

\section{Yann Philippe}

\section{OpenEdition}

\section{Journals}

Édition électronique

URL : http://journals.openedition.org/itti/751

DOI : $10.4000 /$ itti. 751

Éditeur

Université de Poitiers

Référence électronique

Yann Philippe, «Iconographie professionnelle et féminisation du travail policier à New

York (1945-1980) », Images du travail, travail des images [En ligne], 6-7 | 2019, mis en ligne le 01 février

2019, consulté le 14 avril 2021. URL : http://journals.openedition.org/itti/751 ; DOI : https://doi.org/ 10.4000/itti.751

Ce document a été généré automatiquement le 14 avril 2021

Images du travail, travail des images 


\section{Iconographie professionnelle et féminisation du travail policier à New York (1945-1980)}

"The Fairest of the Finest" : Institutional iconography and the feminization of the NYPD (1945-1980)

Yann Philippe

«À cette époque, les femmes policières étaient rares à New York (seulement 338 en 1968 contre plus de 6000 aujourd'hui) et elles étaient encore plus rarement aperçues en public. Aucune d'entre elles n'était affectée au travail en patrouille - cela ne viendrait qu'en 1972 - et donc elles n'étaient presque jamais dans la rue où elles auraient pu être observées par les citoyens. La plupart étaient cantonnées à des fonctions d'assistantes de police, à des tâches de secrétariat ou d'opératrices téléphoniques, à la fouille des femmes prisonnières ou à celle des cadavres féminins dans les commissariats » (Burke, 2006, 47 , je traduis).

1 Avec un brin d'exagération, sans doute destiné à mettre en scène son propre parcours de femme dans l'institution, alors fortement masculine, qu'était le New York Police Department (NYPD), Kathy Burke pose explicitement l'enjeu que représentait à la fin de années 1960 la visibilité du travail policier féminin. Certes présentes dans l'institution, mais fortement minoritaires et affectées presque intégralement à des fonctions spécifiques et peu valorisées, les femmes incarnaient peu l'institution policière dans l'espace public. Dans le NYPD, comme dans de très nombreuses autres forces de police, la montée en puissance des femmes a ainsi constitué la remise en cause d'un «interdit anthropologique», le «quasi-monopole masculin» des «métiers d'ordre» et des 
« institutions en charge d'appliquer la 'violence légitime'«, pour reprendre les mots de Geneviève Pruvost appliqués au cas français (Pruvost, 2008, 7-8). Le NYPD est même resté en retard sur d'autres forces de police urbaines aux États-Unis en termes de féminisation de son personnel et de ses affectations (Schulz, 1995, 124-127 et 145; Darien, 2013, 103-159).

2 Or, depuis les années 1920-1930, le NYPD a entrepris un important processus de production d'images du travail policier, d'abord à travers une revue semi-officielle et à la faible longévité, Police Magazine (1924-1925), puis plus durablement à partir de 1933, par le biais de sa revue institutionnelle, Spring 3100. Dès l'entre-deux-guerres, les chefs de la police new-yorkaise, le plus souvent policiers eux-mêmes, sont en effet convaincus du principe énoncé par le sociologue canadien Jean-Paul Brodeur des décennies plus tard: le "contrôle policier s'exerce au moins autant par la projection symbolique d'une représentation dissuasive de la police que par le recours effectif à la force physique » (Brodeur , 2003, 35). Dès lors, la mise en images du travail féminin pose doublement problème à l'institution policière. Les femmes occupent le plus souvent des fonctions conçues comme périphériques dans la profession, cadrant mal avec le schéma dominant de représentation masculinisée d'une force dissuasive. « $A$ Magazine for Policemen ", le sous-titre de la revue Spring 3100 pendant la plus grande partie de son histoire, illustre cette difficulté. Par ailleurs, l'évolution de la position institutionnelle des femmes au sein du NYPD ne s'est pas faite sans heurt : ce n'est pas l'institution qui a progressivement ouvert ses portes aux femmes mais un certain nombre d'entre elles qui les ont forcées. Si les policières font leur entrée statutaire dans le NYPD au sortir de la Première Guerre mondiale, elles ne réussissent à accéder à l'ensemble des fonctions policières que dans le troisième tiers du XXe siècle et au prix de conflits avec la ville et son institution policière. Jusqu'au milieu des années 1960 en effet, les policières restent cantonnées dans une voie parallèle, le corps spécifique de "femmes policières", sans possibilités d'avancement dans la hiérarchie. Les pionnières, qui réussissent à briser le plafond réglementaire et à accéder aux grades supérieurs, le font par le biais de procédures judiciaires contre leur employeur, la ville de New York et, initialement au moins, contre leur hiérarchie (Melchionne, 1962; Philippe, 2011 ; Schulz 1995).

3 Pourtant, les images du travail féminin produites par Spring 3100 peuvent être considérées comme des archives visuelles à plusieurs titres. Tout d'abord, c'est l'institution policière elle-même qui apparaît très soucieuse de consigner sa propre mémoire, voire son histoire. Elle offre régulièrement à ses lecteurs des aperçus photographiques et nostalgiques sur « la police d'antan ", rendant hommage au travail des « anciens » parmi lesquels figurent, à l'occasion, quelques anciennes. Cependant, on s'attachera moins à ce corpus d'archives photographiques, surgies du passé et souvent difficiles à identifier et à dater précisément, qu'au corpus d'images du travail féminin quotidien produites de manière régulière par la revue du NYPD pour la période 1940-1970. La publication d'une revue officielle, destinée à célébrer l'institution, à diffuser une culture commune à l'ensemble du département autant qu'à séduire ses lecteurs, ne peut se réduire à l'édition promotionnelle des discours de ses dirigeants. Le souci d'établir et de maintenir un lien avec les lecteurs conduit notamment à la production d'une iconographie propre à l'institution, incluant non seulement des photographies, mais aussi des dessins de presse et divers dispositifs participatifs permettant aux lecteurs de contribuer à la signature visuelle de la revue. Les policiers 
de l'équipe éditoriale de Spring 3100 se transforment ainsi en semi-professionnels de la culture visuelle. Cette iconographie interne à la profession, qui s'oppose par exemple aux photographies de commande réalisées dans les usines de la fin du XIXe et du XXe siècles (Assegond, 2012; Lannoy, 2012), fait coïncider les deux pistes de recherche distinguées à des fins méthodologiques par Juliette Rennes: l'étude des métiers de l'image et celle des images du travail (Rennes, 2013a, 409).

Une première direction suivie dans l'article s'intéressera aux conventions de représentation des femmes policières à l'œuvre dans la revue du NYPD. Qu'est-ce que la production institutionnelle d'archives visuelles d'un travail - le travail policier féminin - longtemps vu comme périphérique et mineur au sein du groupe professionnel ? Il s'agira d'identifier un registre iconographique institutionnel et le traitement qu'il offre de la féminisation de la profession, à travers l'accroissement contrôlé de la visibilité des femmes policières.

5 Une seconde direction consistera à examiner dans ses différentes modalités la proposition méthodologique de Juliette Rennes de «mettre en relation, dans leur stabilité et leur recomposition, les imaginaires hégémoniques en matière de rôle sexués et les contextes professionnels où s'élaborent ces imaginaires »(Rennes, 2013a, 409). La prise en compte de la diversité des images dans Spring 3100 (photographies mais aussi dessins de presse) permet en effet de suivre tant les formes de résistance que d'accommodement du groupe masculin face à la féminisation de leur profession. Si l'on souscrit pleinement au constat fait par la socio-historienne que les « représentations visuelles antagonistes constituent une partie intégrante, souvent négligée, des ressources mobilisées" dans les conflits liés à la mobilisation des métiers historiquement réservés aux hommes (Rennes, 2013a, 409-410), il semble que certaines représentations visuelles - que l'on ira cependant pas jusqu'à qualifier d'amicales sont également une ressource peu mobilisée dans la prise en compte des formes d'acceptation - progressive et partielle - des femmes par leurs collègues masculins.

6 Enfin, la comparaison des images produites dans la revue historiquement masculine qu'est Spring 3100 avec le travail photographique réalisé par une femme photographe extérieure à l'institution, Jane Hoffer, à la fin de notre période d'étude, offre la possibilité d'évaluer de manière rétrospective et réflexive le caractère masculin de la culture visuelle du NYPD. On se demandera si celle-ci a pu représenter, en dépit des contraintes, un lieu d'expression et de contribution des policières à la vie de l'institution et au modelage de leur propre identité.

7 Notre analyse, tout en étant issue de l'historiographie de la police, tentera de se situer au croisement de celle-ci et des études visuelles, dans le souci de faire dialoguer deux champs souvent peu mis en relation. In fine, c'est donc le regard de l'historien ou de l'historienne qui, loin de rejeter la production d'une revue institutionnelle dans l'insignifiance d'une littérature promotionnelle - tendance fréquente dans l'historiographie policière - constitue ces documents iconographiques divers en archives visuelles ${ }^{1}$. 


\section{Iconographie institutionnelle et visibilité du travail policier féminin}

Les archives visuelles produites par la revue du NYPD fonctionnent tout d'abord comme des balises institutionnelles de la progression des femmes dans l'institution policière masculine. Elles sont, à ce titre, le fruit d'une production contrôlée qui joue sur les différentes figures représentées par les policières : à la fois membres de l'institution, femmes et mères.

\subsection{Des « jalons significatifs » dans l'histoire institutionnelle des femmes au sein du NYPD}

Bien moins présentes visuellement que les hommes dans l'ensemble de la revue Spring 3100 , les femmes le sont encore moins sur les illustrations de couverture. Celles-ci montrent quasi exclusivement des hommes, qu'ils soient seuls en patrouille dans la tempête en hiver ou dans la chaleur de la ville en été, au contact de la population pour aider ou arrêter des individus ou encore aux commandes des différents véhicules de l'institution (automobiles, moto, hélicoptères). Les rares illustrations de couverture mettant en scène des femmes acquièrent dès lors une charge visuelle significative. Le fossé qui sépare la couverture de novembre 1933 de celle d'avril 1973 révèle l'avancée réalisée en une quarantaine d'années par les policières du NYPD. Le dessin qui illustre le numéro de novembre 1933 montre une scène tout à fait improbable :

Dessin $n^{\circ} 1$

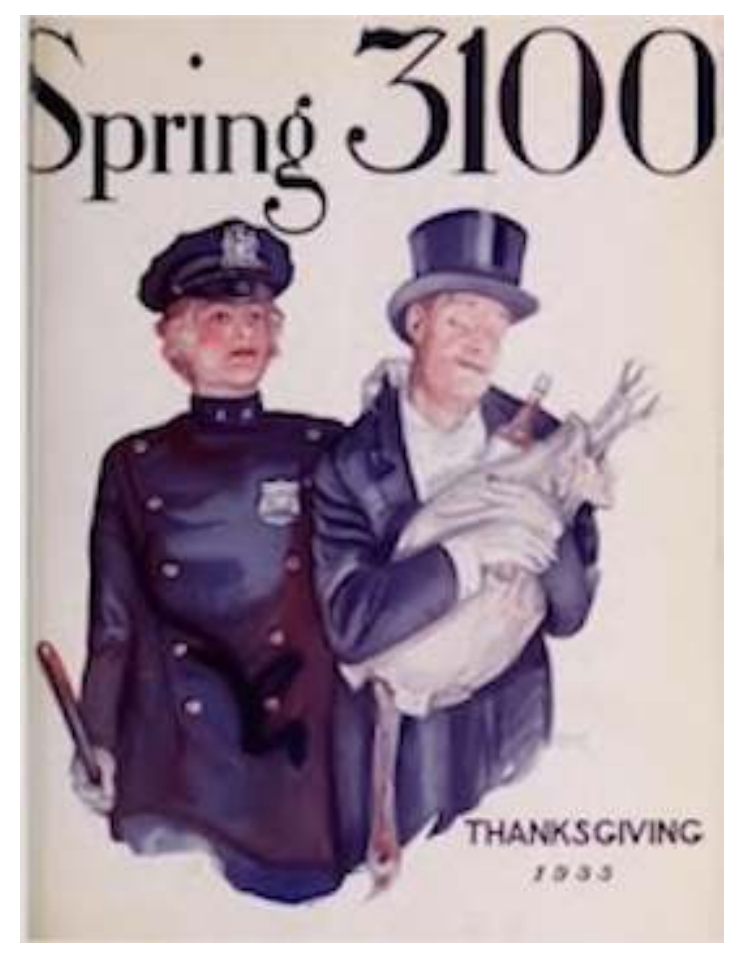

Spring 3100, novembre 1933, couverture 
Une jeune policière, aux cheveux blonds et aux lèvres peintes, affublée d'attributs masculins (uniforme, casquette, matraque) agrippe par le col un homme aisé, amoindri par l'alcool, tenant une dinde emballée dans du papier, qui va fêter Thanksgiving ou vient de le célébrer. Le dessin (toutes les couvertures de l'époque sont alors dessinées) fait surgir une image impossible, produite et comprise comme telle, carnavalesque en quelque sorte. Les femmes policières sont alors rarement en uniforme, ne disposent pas d'attributs professionnels masculins et ne s'occupent pas d'arrêter les hommes : leur mission ne consiste pas à patrouiller mais essentiellement à réguler le comportement des femmes et des enfants. Quarante ans plus tard, la portée documentaire de l'illustration ouvrant l'édition d'avril 1973 est indéniablement plus forte :

\section{Photographie $n^{\circ} 1$.}

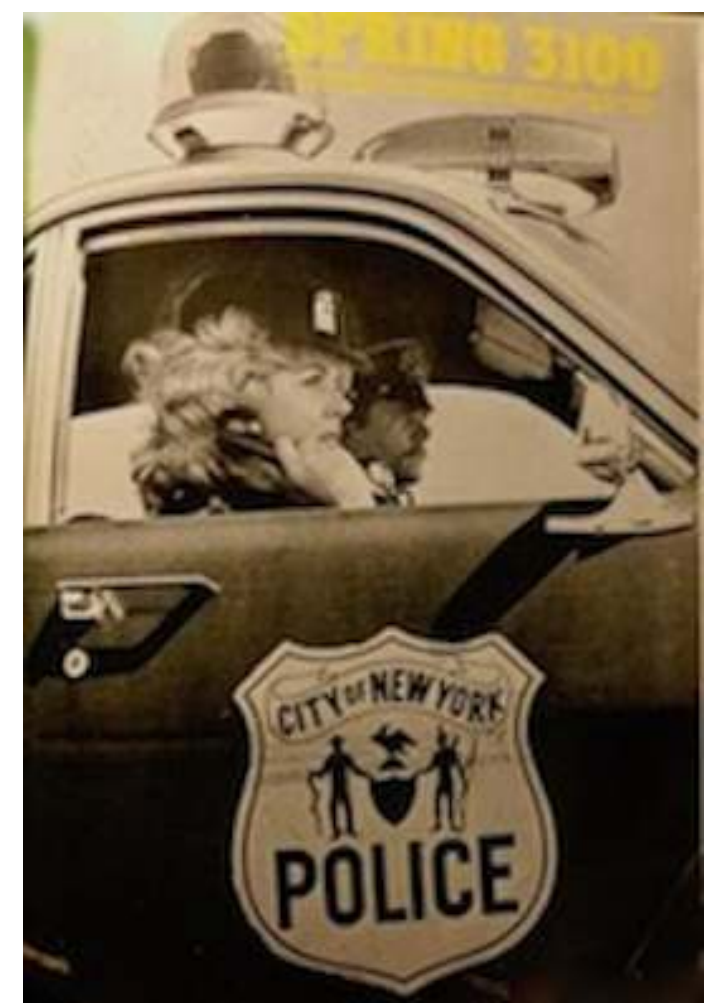

Spring 3700, avril 1973, couverture

11 La différence ne tient pas principalement au passage du dessin à la photographie mais à un changement de registre. Au-delà de la blondeur commune aux deux femmes, on est passé d'une représentation fantasmatique à la mise en images d'une pratique réelle, révélant la place prise par les femmes dans l'ordinaire policier : les femmes patrouillent désormais en compagnie des hommes, et occupent des fonctions théoriquement équivalentes (Darien, 2013, 115-128). Certes sur cette image, l'agent masculin est placé dans le champ de l'action - il conduit la voiture de patrouille - tandis que l'agent féminin se situe dans le champ de la communication - elle est au téléphone. Mais la photographie illustre le changement de statut des policières. La prise de vue en contreplongée ainsi que la place de la femme au premier plan inscrivent celle-ci dans la continuité de l'emblème du NYPD sur la portière de la voiture. La terminologie officielle depuis 1972 fait référence à des " agents de police » (" police officer») et non plus à des "policiers" et des "policières" (même si le sous-titre de la revue n'enregistre le 
changement qu'un an plus tard en avril 1974). Parcourir Spring 3100, c'est donc parcourir l'histoire de l'avancée des femmes dans l'institution policière.

Photographie $n^{\circ} 2$.

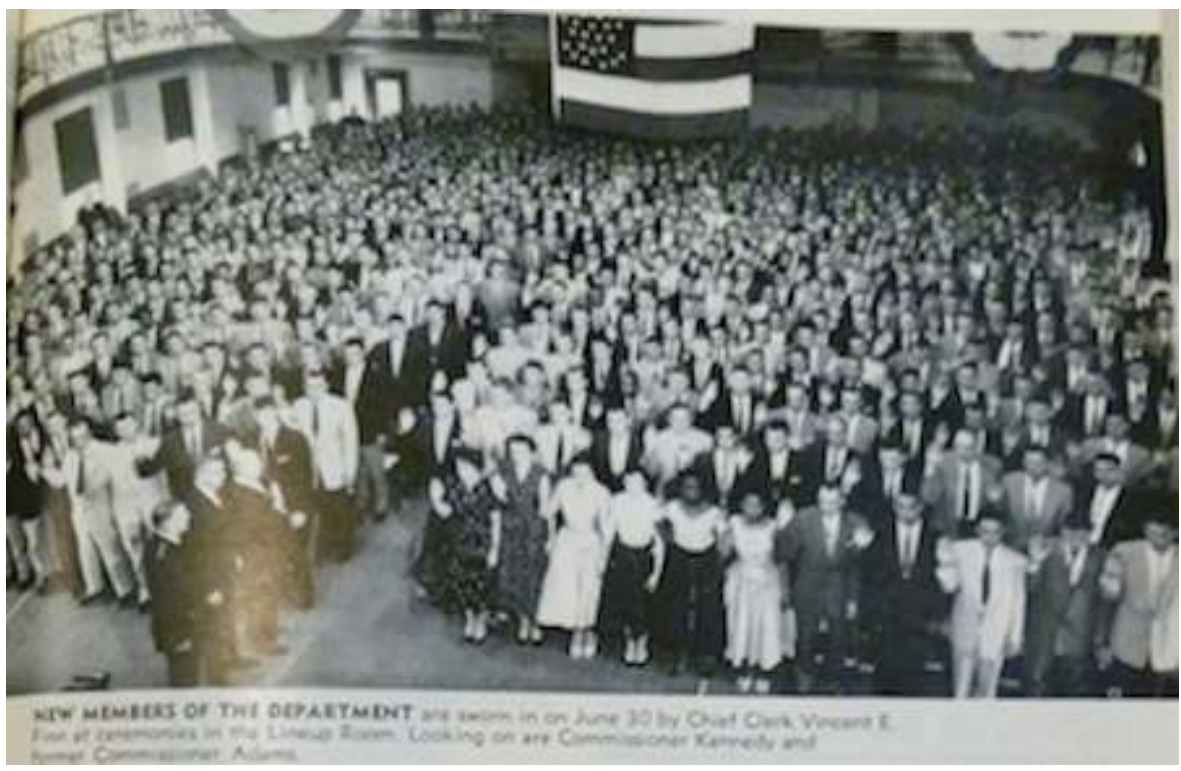

Spring 3100, septembre 1955, p. 19

Photographie $n^{\circ} 3$.

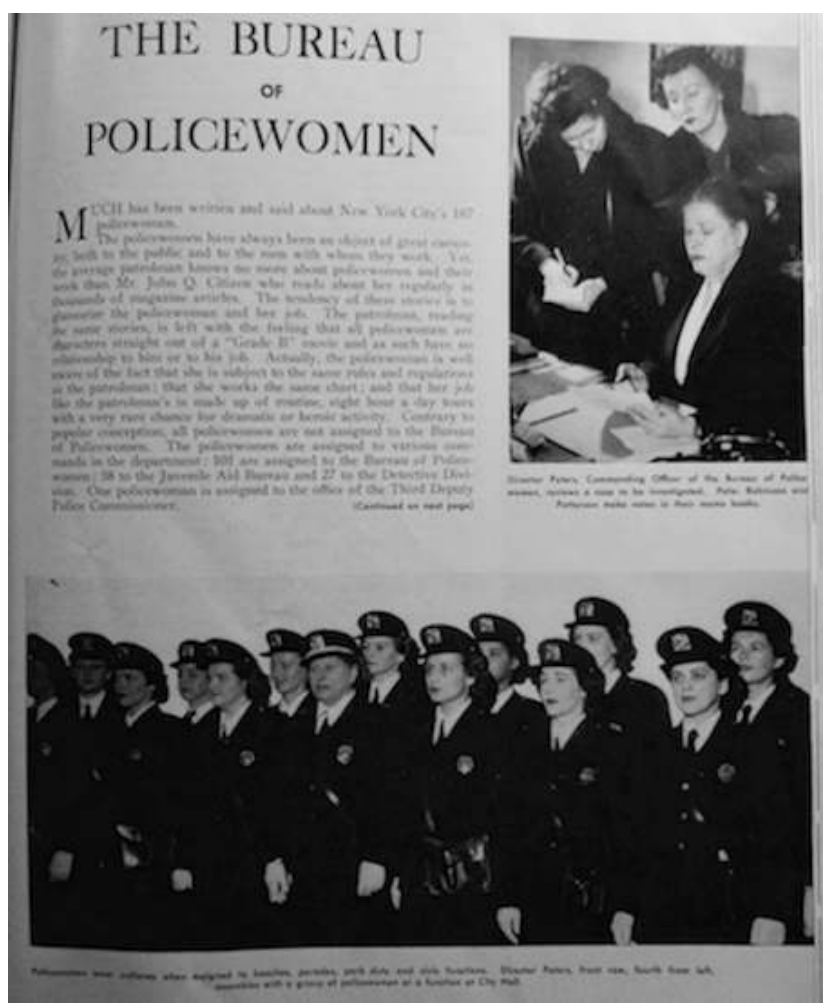

Spring 3100, juillet-août 1950, p. 21

Produits de l'institution, les archives visuelles publiées dans Spring 3100 mettent d'abord en scène la vie de l'institution et alternent images de groupes entiers, d'unités de 
travail spécialisées et d'individus. Cette alternance, comparable à celle mise en œuvre dans la photographie d'usine du début XXe siècle, sert la stratégie de promotion du NYPD. Elle projette l'image rassurante d'une institution à la fois unie, hiérarchique et fonctionnelle. Dans cet « organigramme idéalisé ", pour reprendre la formule de Céline Assegond, les policières ont une place réduite mais spécifique (Assegond, 2012, 92-98). L'entrée officielle dans le département lors des cérémonies de sortie de l'école de police fait, chaque année, l'objet d'un reportage. La mise en scène des photographies de promotion (en civil ou en uniforme selon les années) célèbre l'effet de masse et d'unité. Les femmes sont minoritaires (voire absentes certaines années) mais placées systématiquement au premier rang, comme on peut le voir sur la photographie $n^{\circ} 2$. L'unité de police féminine (photographie $\mathrm{n}^{\circ} 3$ ) fait l'objet de reportages relativement réguliers (avril 1950, juillet-août 1950, juillet-août 1954, juillet-août 1959, février 1964, juillet-août 1965, juillet-août 1968) qui montrent à la fois la directrice et certaines des policières qui y sont affectées. La publication dans la rubrique «Down the Line: News About Police Organizations » de l'organigramme de l'association des femmes policières (la Policewomen's Endowment Association) et des manifestations diverses que celle-ci organise, ou la couverture des diverses manifestations de charité sont enfin des occasions de publier des photographies individuelles et nominatives de policières. La policière la plus représentée dans la revue est ainsi très probablement Theresa Melchionne qui cumule tous les motifs de légitimité jusqu'à sa retraite en septembre 1971 : elle est, en effet, directrice du Bureau de la police féminine ( Policewomen's Bureau ») de 1952 à 1963, puis adjointe au haut-commissaire de 1963 à 1971 (en charge des opérations pour la jeunesse, puis des relations avec les minorités)².

Une visibilité spécifique est accordée également aux "pionnières»: celles qui ont réussi à briser le plafond institutionnel et à gravir les échelons de la hiérarchie, non par désignation comme Melchionne (devenue adjointe au haut-commissaire), mais par la voie méritocratique des concours de promotion, ouvrant l'accès aux positions de sergent, lieutenant et commissaire, Gertrude Schimmel et Felicia Shpritzer : 
Photographie $n^{\circ} 4$.

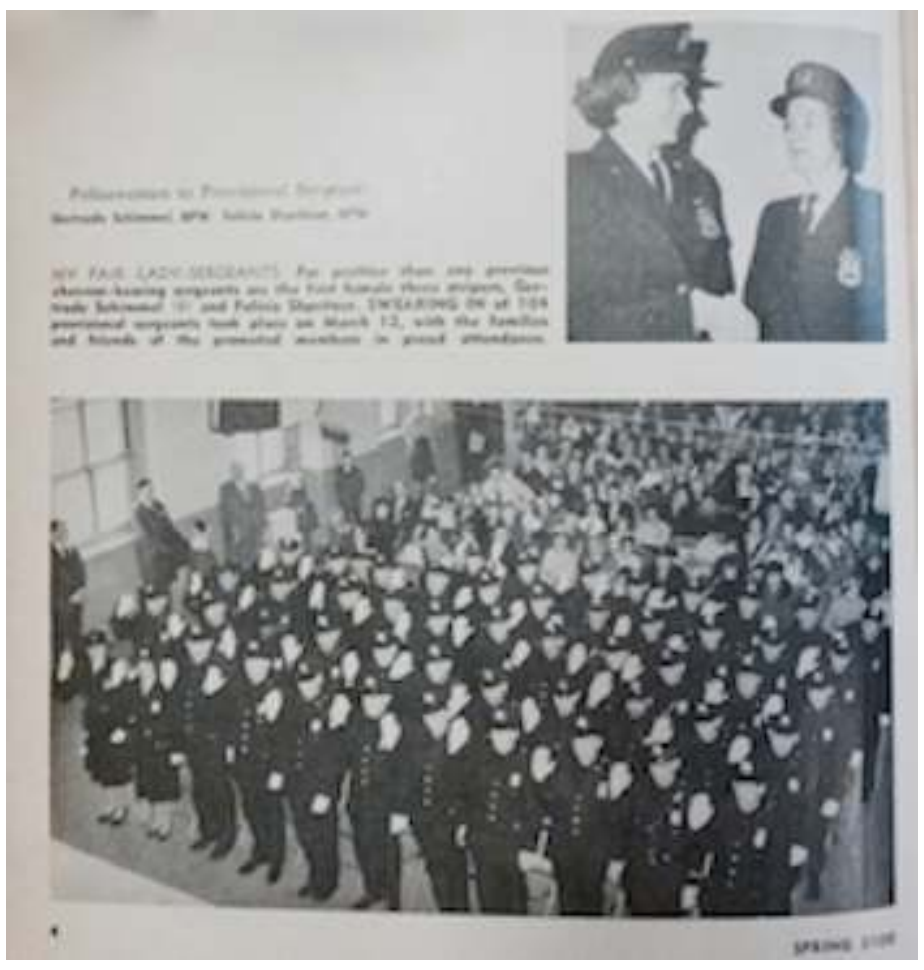

Spring 3100, avril 1965, p. 4

Photographie $n^{\circ} 5$.

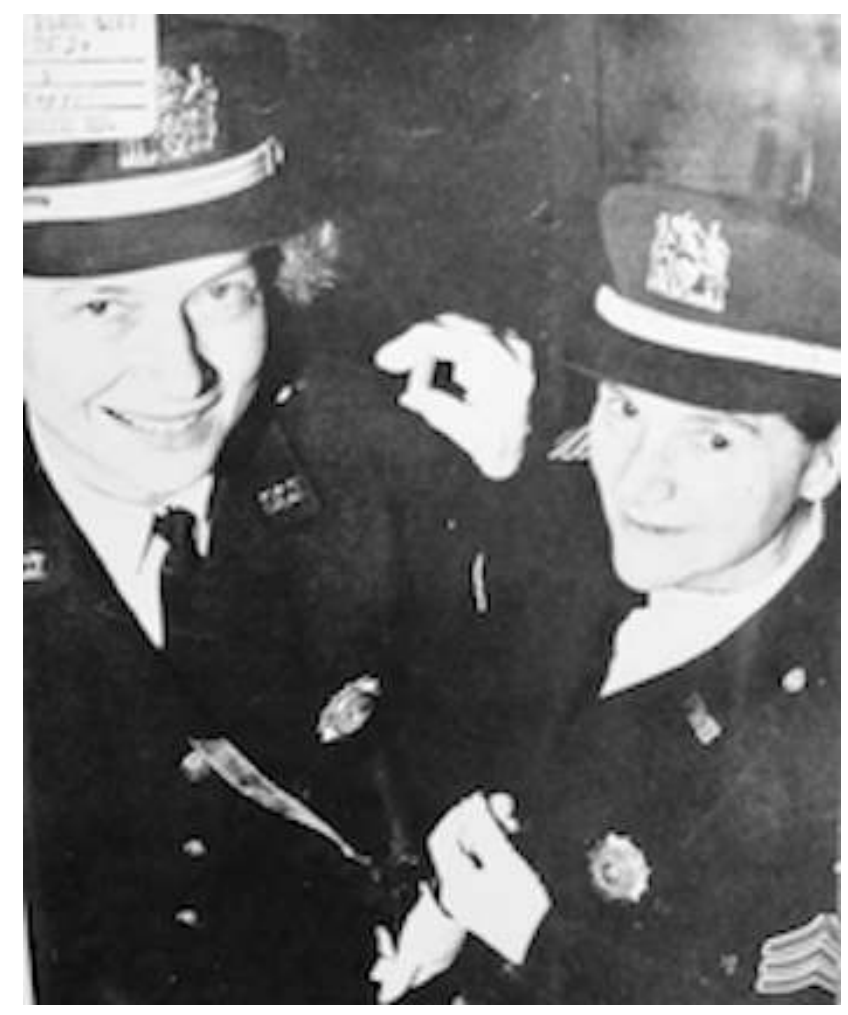

Spring 3100, Janvier 1968, couverture 
14

En avril 1965, Spring 3100 centre son reportage sur les cérémonies de promotion du mois précédent autour des deux jeunes femmes qui viennent d'accéder pour la première fois dans l'histoire du NYPD au grade de sergent (photographie $n^{\circ} 4$ ). En janvier 1968, les deux femmes figurent en couverture de la revue, à l'occasion de leur accession au grade de lieutenant: l'une d'elles met bien en évidence le galon de l'autre pour témoigner d'une fierté professionnelle durement acquise (photographie $n^{\circ} 5$ ).

Ces choix éditoriaux peuvent, pourtant, surprendre pour une revue institutionnelle. Shpritzer est, en effet, la policière qui a assigné en justice la ville et obtenu le droit de se présenter en tant que femme aux concours de promotion interne. La procédure, enclenchée en 1961, arrive à son terme en 1963 et, au printemps 1964, le premier concours de sergent ouvert aux femmes est organisé. Des 127 femmes candidates, six réussissent le concours et deux, Shpritzer et Schimmel, sont effectivement promues (une troisième est promue à l'automne 1965)3. Dans le numéro d'avril 1965, le reportage de Spring 3100 cite le discours prononcé par le haut-commissaire à la police, à l'occasion de la cérémonie de promotion de ces deux pionnières. Michael J. Murphy célèbre l'accession des deux jeunes femmes au grade de sergent et qualifie l'événement de «jalon significatif dans l'histoire de notre département : l'émergence de nos policières sorties du rang $»^{4}$. Pourtant, lors du dépôt de la plainte de Shpritzer, le même Murphy s'était exprimé en justice et dans la presse, estimant que les femmes ne disposaient pas de la force physique et de l'endurance nécessaires pour être sergent de police ${ }^{5}$. Par effet de continuité institutionnelle, l'autorité policière s'approprie ainsi le changement et célèbre publiquement ces "pionnières ". Cependant, même dans leur diversité, ces représentations sont moins des archives du travail des femmes que des archives de leur présence dans l'institution.

\subsection{Des images de femmes dans l'institution ou de policières au travail ?}

Les femmes sont très rarement visibles dans la rubrique "All in the day's work » qui constitue l'un des premiers reportages du magazine et qui expose les diverses facettes de travail policier quotidien: interventions lors d'accidents, arrestations, sauvetages, interactions diverses avec la population. Le dessin suivant sert pendant quelques mois avec d'autres dessins mettant en scène des hommes - de logo à la rubrique. Mais son existence brève illustre la difficulté à représenter régulièrement le travail quotidien des policières :

Images du travail, travail des images, 6-7 | 2019 
Dessin $n^{\circ} 2$

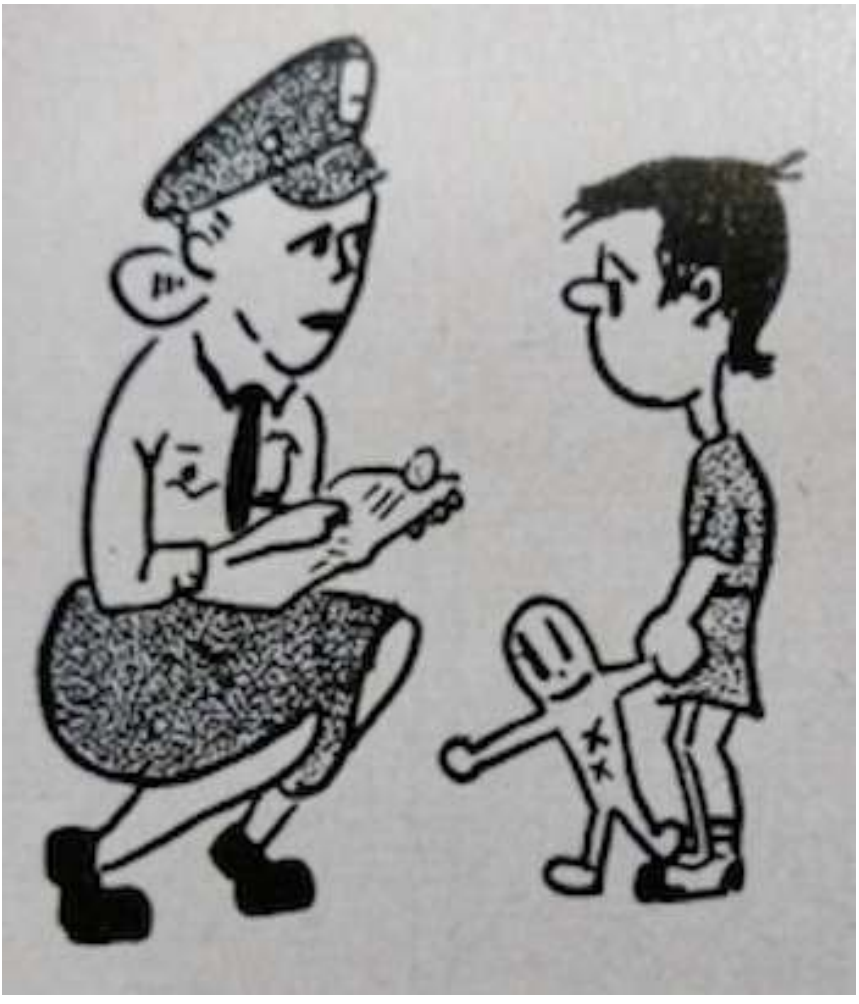

Spring 3100, février 1954, p. 10

17 Les photographies montrant des femmes au travail sont le plus souvent posées, plutôt que prises sur le vif : 
Photographie $n^{\circ} 6$.

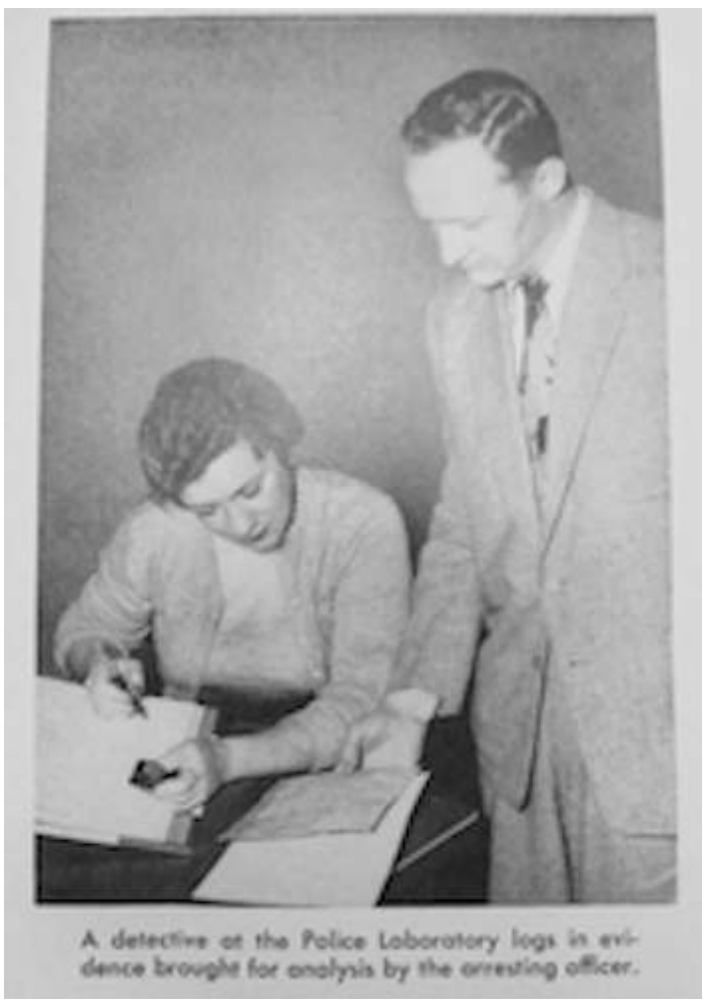

Une policière enregistre des preuves dans une affaire de stupéfiants Spring 3700, novembre 1954, p. 4 


\section{Photographie $n^{\circ} 7$.}

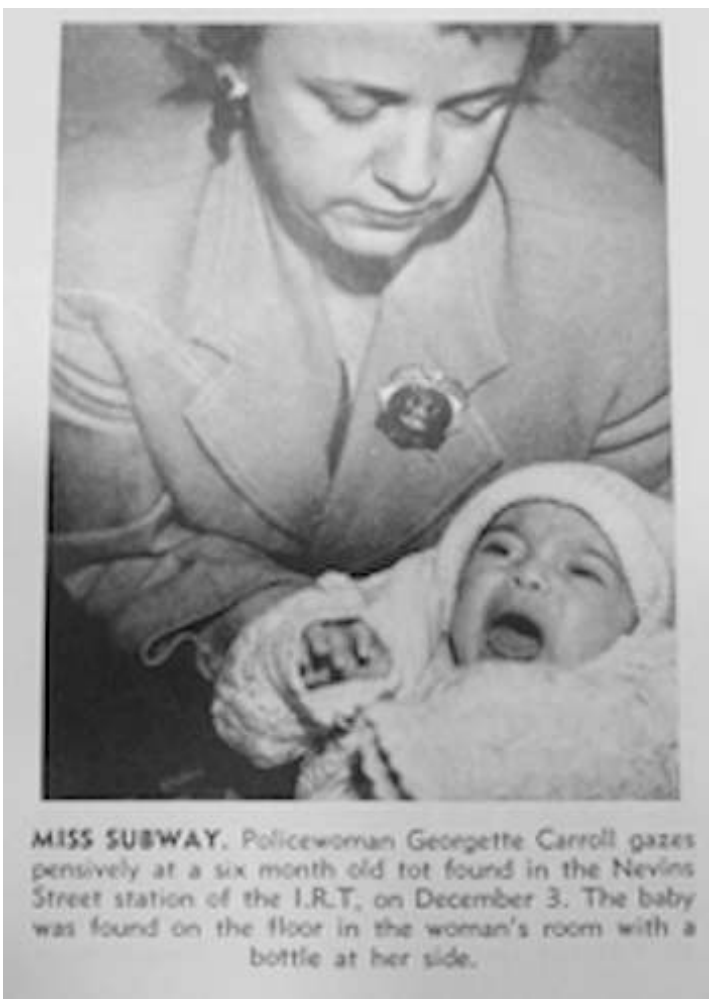

Une policière s'occupe d'un enfant abandonné

Spring 3100, janvier 1955, p. 15

18 Les situations de travail représentées correspondent à des tâches pensées comme en partie annexes ou secondaires : l'enregistrement et non l'obtention des preuves, la prise en charge d'enfants abandonnés plutôt que la patrouille ou la lutte contre la criminalité. Les policières sont donc assignées à des tâches considérées comme féminines (le secrétariat, le «care »). Tant dans leur distribution minoritaire dans la revue que dans les sujets qu'elles mettent en scène, ces photographies ne remettent pas en cause la conception dominante du métier comme activité masculine. La photographie $n^{\circ} 8$, par le rapprochement qu'elle semble opérer entre une policière et une religieuse, livre un raccourci saisissant: les policières ne sont présentes dans l'institution que pour remplir des fonctions spécifiques, ce sont d'abord des mères sociales, des nonnes en uniforme de la ville de New York. 
Photographie $n^{\circ} 8$.

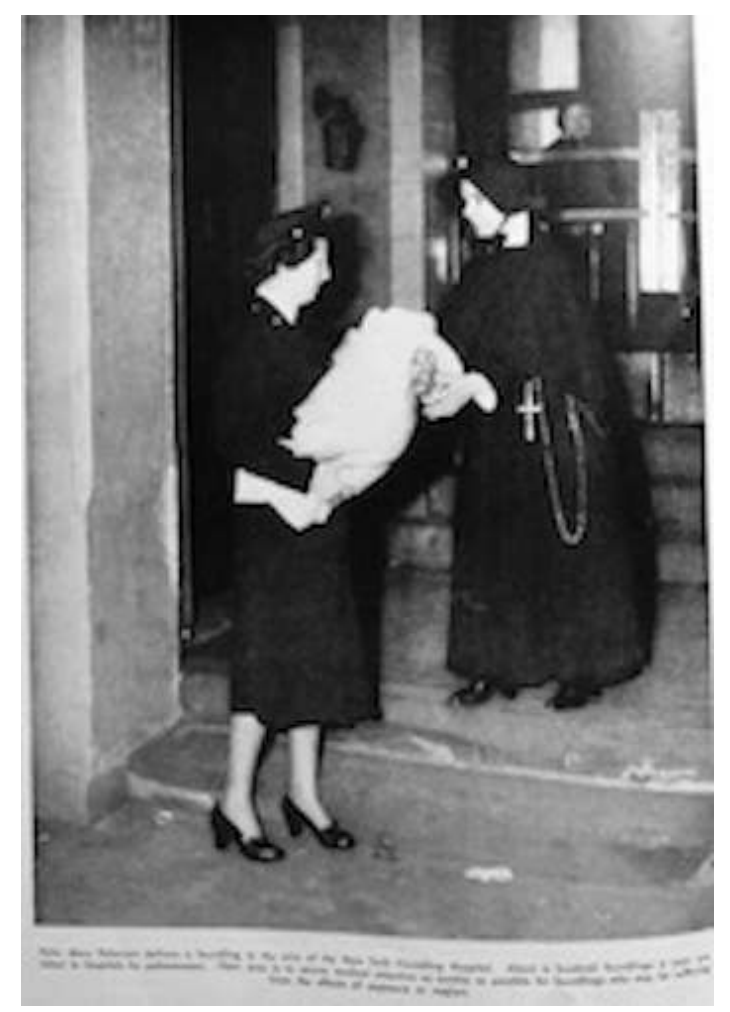

Une policière remet un enfant à une religieuse à la porte d'un hôpital pour enfants

Spring 3100, juillet-août 1950, p. 20

19 Aussi les photographies saisissant des policières aux prises avec un événement sontelles rares. Dans la période 1950-1960, riche en protestations, on ne trouve que quelques images de policières en pleine activité lors de manifestations de rue (deux sont reproduites ci-dessous). Ce sont, d'ailleurs, des photographies fournies par des agences de presse et non par des photographes du NYPD. Elles renvoient, cependant toujours, à l'une des missions spécifiques des femmes policières, qui est de s'occuper des femmes (de la même façon qu'elles interviennent en cellule quand un individu féminin est arrêté par un policier). 
Photographies $n^{\circ} 9$ et $n^{\circ} 10$.

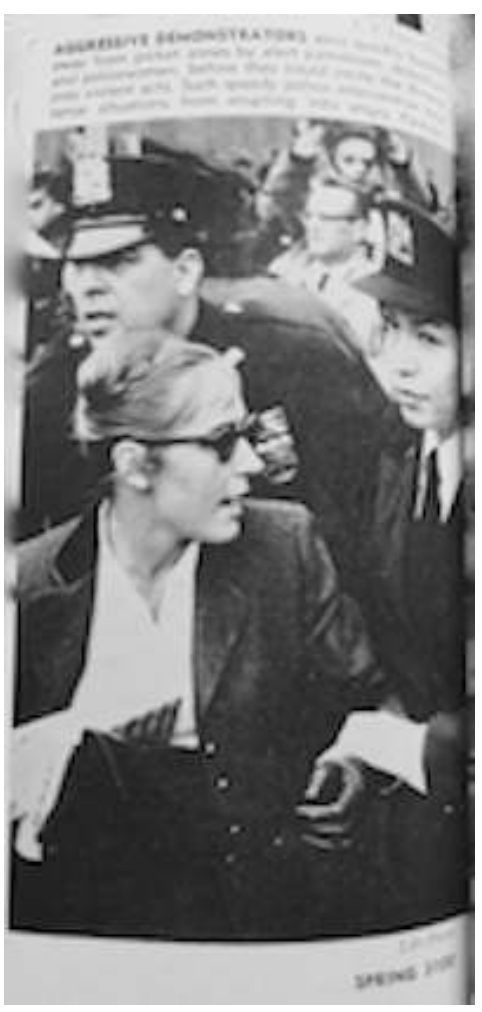

Photographie $n^{\circ} 10$.

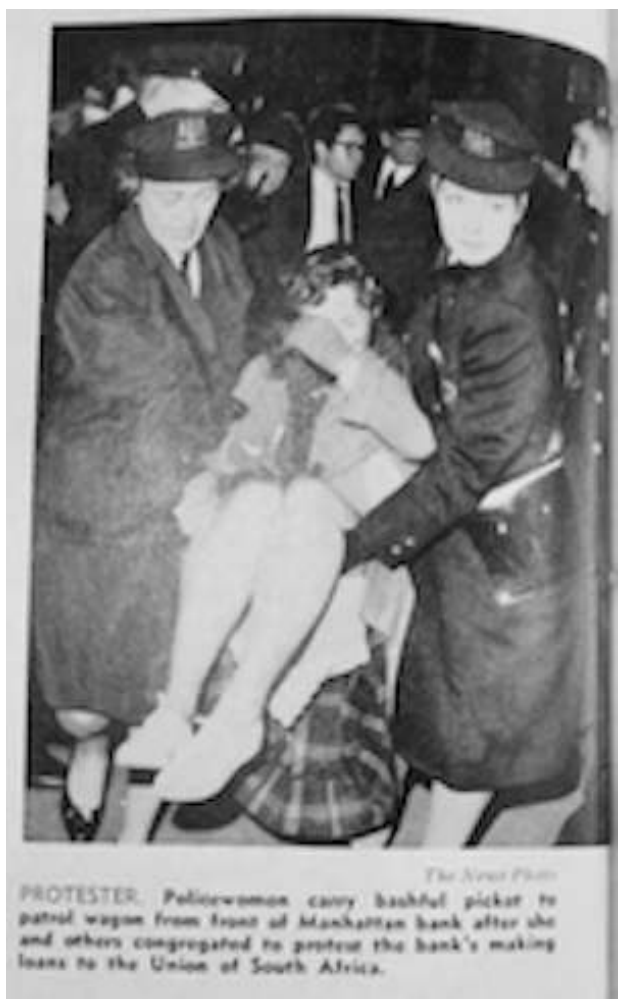

Des policières arrêtent des manifestantes

Spring 3100, novembre 1960, p. 23 et mai 1965, p. 8 
D'autres images, plus exceptionnelles encore, montrent des arrestations opérées par des femmes sur des hommes. Elles mettent, toutefois, précisément en scène l'effet de révélation de l'identité policière de ces femmes. Ainsi, des cambrioleurs surpris par la présence inopinée de celles qu'ils pensaient être de simples ménagères :

Photographies $n^{\circ} 11$ et $n^{\circ} 12$.

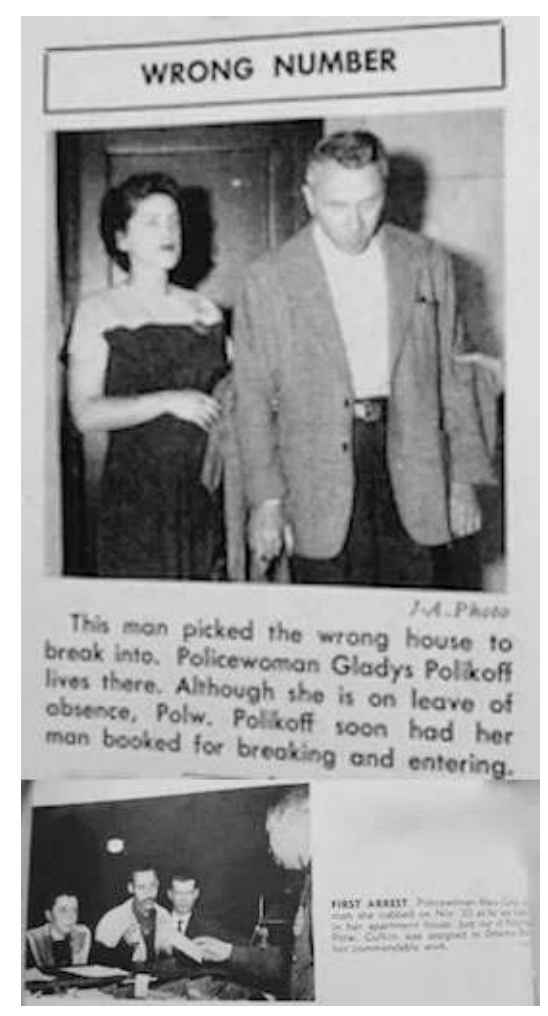

Arrestation d'un cambrioleur par une policière

Spring 3100, septembre 1950, p. 14 et janvier 1960, p. 8 
Photographie $n^{\circ} 13$.

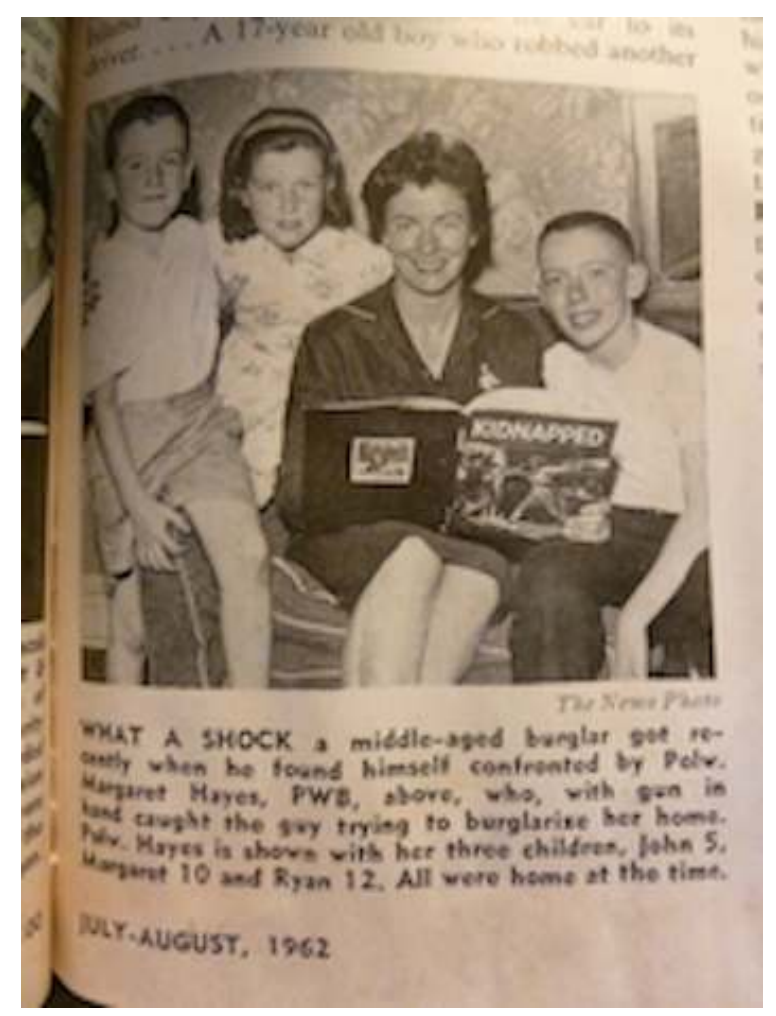

Une policière en famille après l'arrestation d'un cambrioleur Spring 3700, juillet-août 1962, p. 15

21 Cette activité, opérée de surcroît par des policières à leur propre domicile, reste à la marge. Elle fonctionne d'autant mieux qu'elle relève de l'effet de surprise et sa généralisation mettrait en garde les cambrioleurs autant qu'elle affaiblirait la valeur de l'information. La photographie $n^{\circ} 13$ reproduite par la revue neutralise, d'ailleurs, immédiatement la portée exceptionnelle de l'événement en présentant une autre image, celle rassurante d'une mère de famille, tranquille et radieuse en présence de ses enfants auxquels elle lit des histoires. Si les policiers sont également souvent montrés dans la revue en compagnie de leur famille, c'est bien plus souvent dans le cadre de cérémonies publiques, notamment lors de la remise de récompenses professionnelles, que dans le cadre privé. Enfin la promotion de Mary Culkin (la légende de la photographie $\mathrm{n}^{\circ} 12$ reproduite en note ${ }^{6}$ ) renvoie à la présence attestée de policières au sein du Bureau des détectives mais en signale le caractère extraordinaire puisque c'est un exploit individuel qui a valu cette promotion à la policière.

Dernière possibilité ouverte à l'ouverture du registre des tâches policières féminines : un événement exceptionnel, comme la grève dans les transports public new-yorkais en janvier 1966. De façon ponctuelle et pour la première fois dans l'histoire du NYPD, des policières furent appelées, à la rescousse de leurs collègues masculins pour réguler le trafic routier : 
Photographie $n^{\circ} 14$.

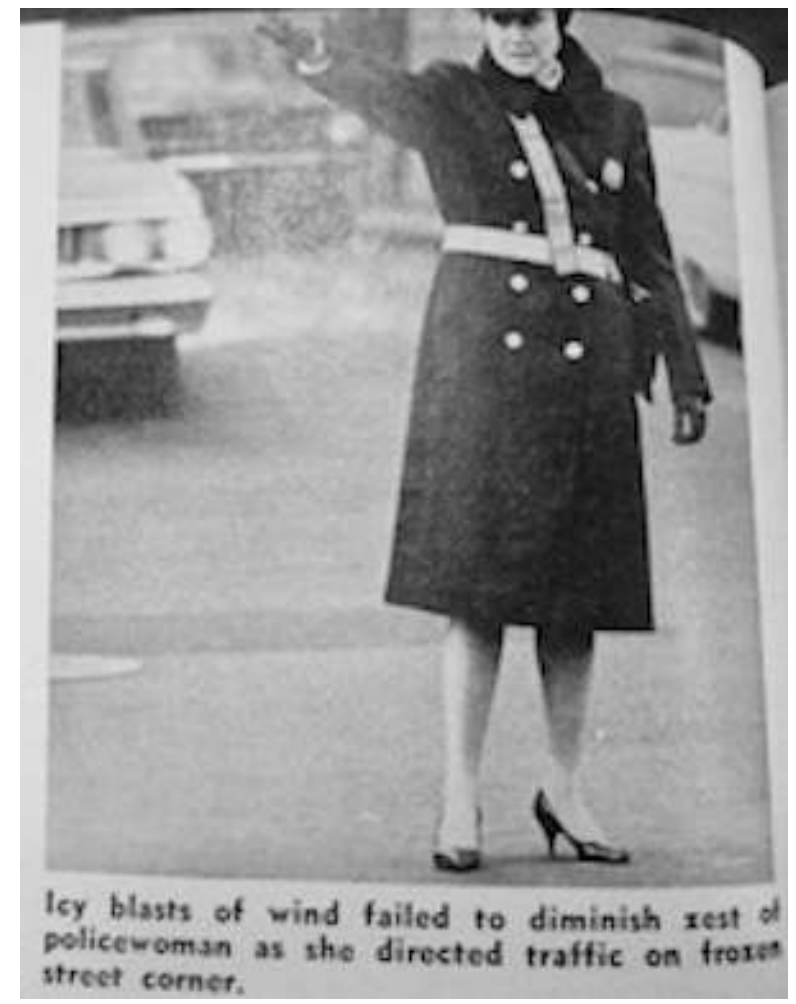

Des policières appelées à réguler le trafic routier

Spring 3700, février 1966, p. 24

23 Dans l'ordinaire du travail, les policières restent donc avant tout des femmes dans le regard de leurs collègues masculins.

\section{3 " The Fairest of the Finest » : regards masculins sur le travail policier féminin}

Photographies $n^{\circ} 15$ et $n^{\circ} 16$

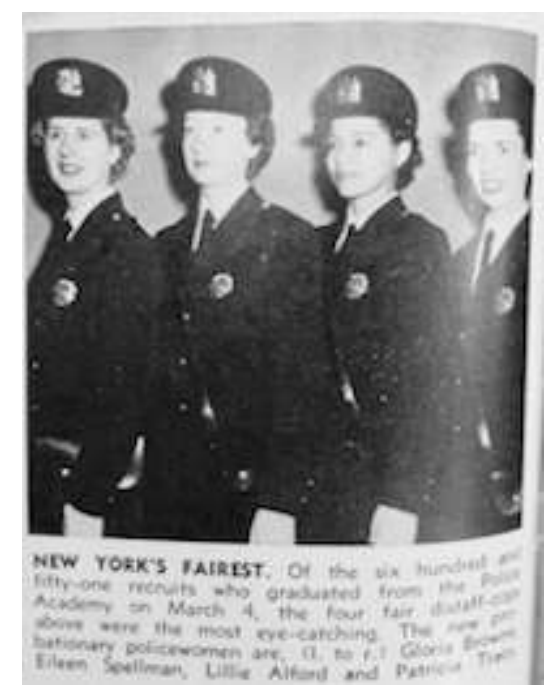




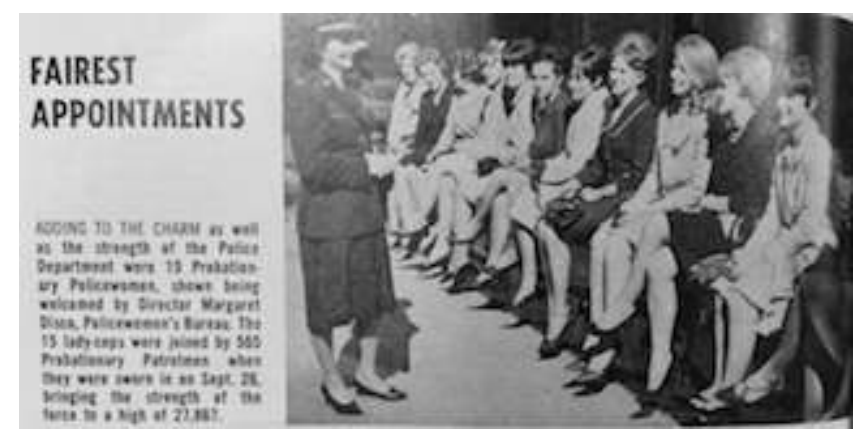

Spring 3700, avril 1957, p. 4 et Novembre 1966, p. 6 sergents soulignent une permanence dans la désignation des femmes policières. York's Fairest ", " The Fairest of the Finest » (" Les plus belles des meilleures »)! Modelée sur le surnom attribué aux policiers new-yorkais depuis le XIXe siècle, « New York's Finest» («Les meilleurs de New York»), la désignation couramment adoptée dans Spring 3100 pour évoquer les policières dans les années 1950-1960 révèle l'identité spécifique de celles-ci au sein de l'institution policière new-yorkaise. Si l'expression est, sans doute, vue comme laudatrice par ses utilisateurs masculins, elle illustre la place réservée et délimitée qui est laissée par les hommes aux femmes, aussi appelées " dames policières" ( lady cops »). Celles-ci font bien partie du groupe policier mais restent à part, définies d'abord par leur identité de femme et singulièrement par leur apparence physique. De fait, Spring 3100 est une revue quasi exclusivement dirigée par des hommes. Une seule policière, Yetta Cohn, fait partie de l'équipe éditoriale entre janvier 1950 et septembre 1953. Il n'a plus ensuite de membre féminin jusque dans les années 1970. Spring 3100 offre donc un regard masculin sur le travail des policières.

La légende de la photographie d'avril 1965 montrant la promotion au grade de sergent de Schpritzer et Schimmel, colle aux postulats sexistes de l'époque : "Belles femmes sergents. Bien plus jolies que n'importe quel porteur précédent de chevron sont les premières femmes aux trois galons » (Spring 3100, avril 1965, 4).

L'accession des femmes à un rang hiérarchique inédit est visuellement traitée sous l'angle du charme de l'éternel féminin ${ }^{7}$. Cet angle pittoresque dans le reportage se retrouve par exemple dans l'évocation du sac d'une policière en 1950 : 


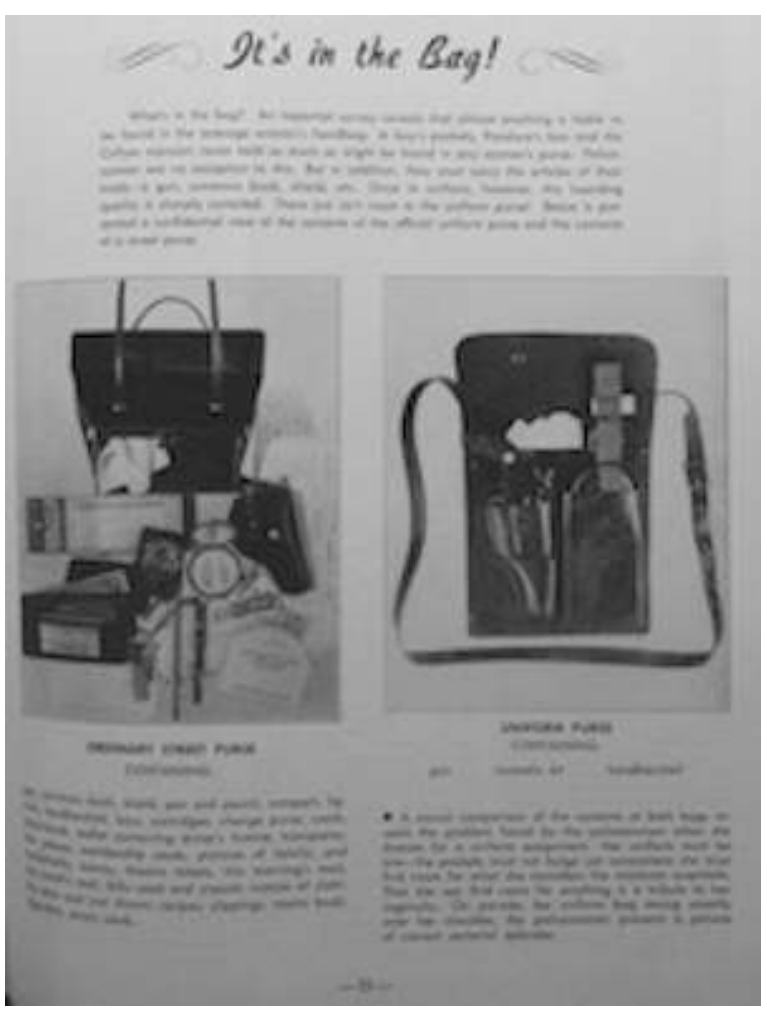

Spring 3700, février 1950, p. 23

27 La légende accompagnant le dessin reprend le stéréotype répandu du sac à mains plus profond que la boite de Pandore (« Une enquête impartiale montre que presque tout est susceptible de se retrouver dans le sac à main ordinaire d'une femme »). Surtout, elle met l'accent sur les conséquences professionnelles des habitudes de genre : « La simple comparaison du contenu des deux sacs montre le problème rencontré par une policière quand elle s'habille pour une mission en uniforme $»^{8}$. Si les policières restent femmes, être policière consiste, cependant, à renoncer à une partie des attributs qui font la féminité domestique et qui n'ont pas de place dans le sac policier réglementaire (portemonnaie, photos de famille, courrier, factures, recettes etc..) pour ne conserver que le minimum indispensable des attributs policiers féminins (arme de service, nécessaire de maquillage, mouchoir). Pouvoir se défendre d'un côté, pouvoir se maquiller, se moucher ou sécher ses larmes de l'autre, sont les deux pôles de l'identité policière féminine. Là encore, la féminité est ramenée à sa dimension corporelle.

Les attributs physiques des policières sont ainsi régulièrement mis en avant dans les colonnes de la revue, dans le texte ou dans la sélection des images. Cela est particulièrement vrai lors du gala donné par l'association de la police féminine (Policewomen's Endowment Association), propice à une mise en spectacle des corps policiers féminins pouvant emprunter au folklore du Western ou du French cancan : 
Photographies $n^{\circ} 18$ et $n^{\circ} 19$.

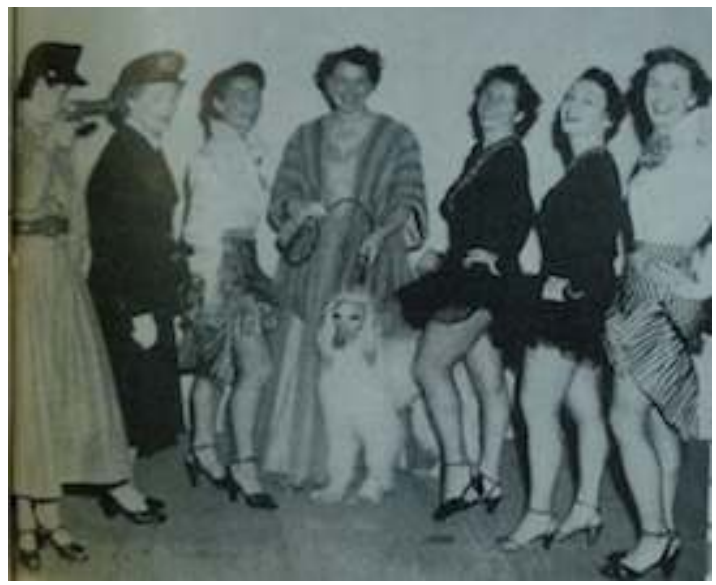

Photographie $n^{\circ} 19$.

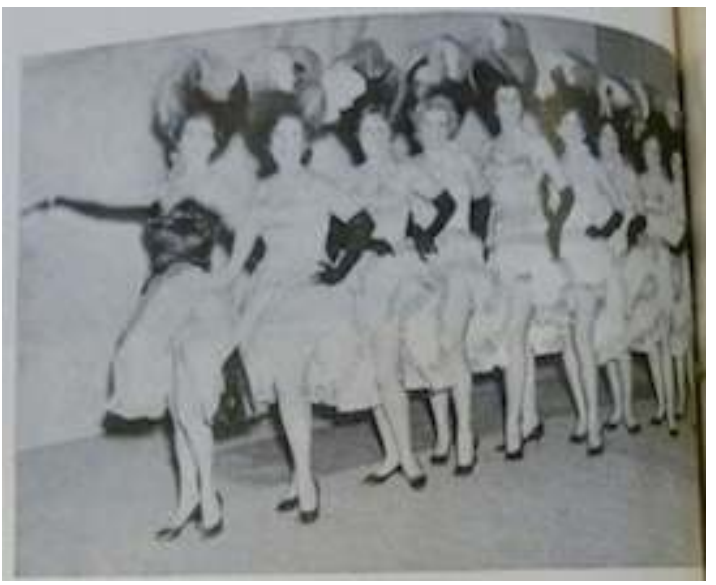

Spring 3100, juin 1954, p. 39 et juin 1964, p. 24

Photographie $n^{\circ} 20$.

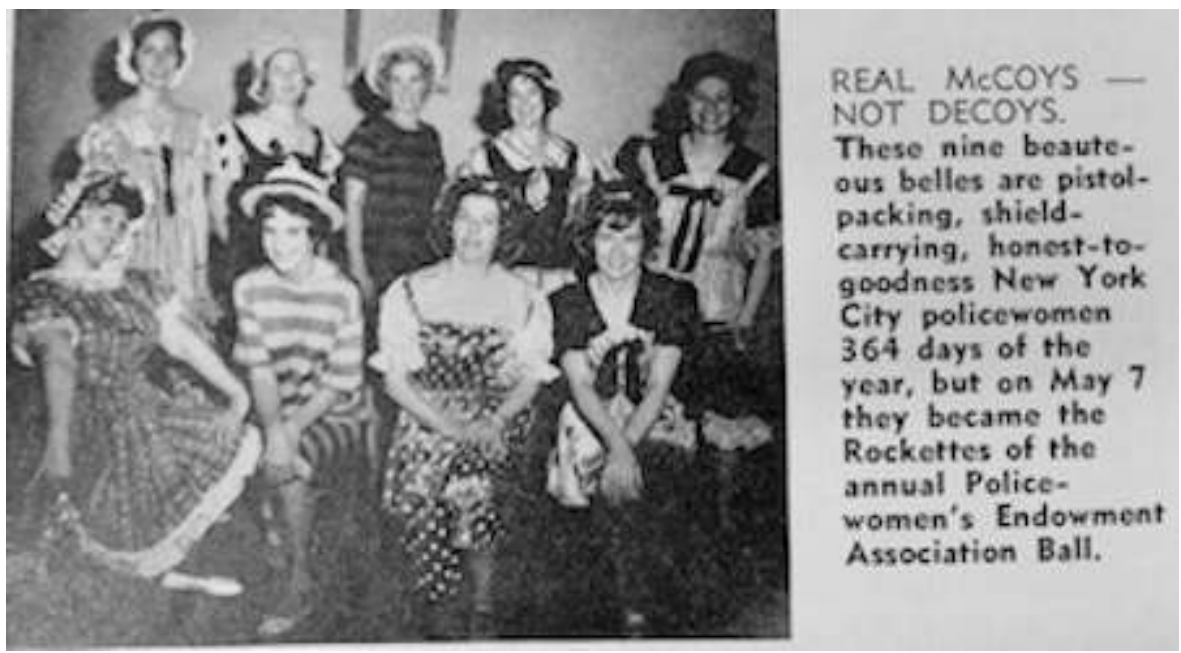

Le gala annuel de l'association de la police féminine Juin 1963, p. 42 
À grand renfort de jeux de mots, les légendes de ces photographies soulignent que les protagonistes du spectacle sont bien des femmes (et non des policiers déguisés en femme appelés "decoys») et/ou qu'elles ont de bien jolies jambes (légende de la photographie $\left.n^{\circ} 19\right)$. Les lecteurs masculins qui achèteraient des billets pour le spectacle en auraient pour leur argent! Mais des photographies au caractère plus officiel comme les $n^{\circ} 15$ et 16 reproduites plus haut insistaient pareillement sur la beauté des recrues et/ou mettaient visuellement en avant leurs jambes. De plus, quelques années plus tard, dans le numéro de janvier 1968 qui place Schimmel et Spritzer en couverture à l'occasion de leur promotion au rang de lieutenant, une brève met l'accent sur les talents de mannequins de certaines policières (photographie $n^{\circ} 21$ ) lors d'opérations de bienfaisance destinées à récolter des fonds pour la communauté noire ${ }^{9}$.

Photographie $n^{\circ} 21$.

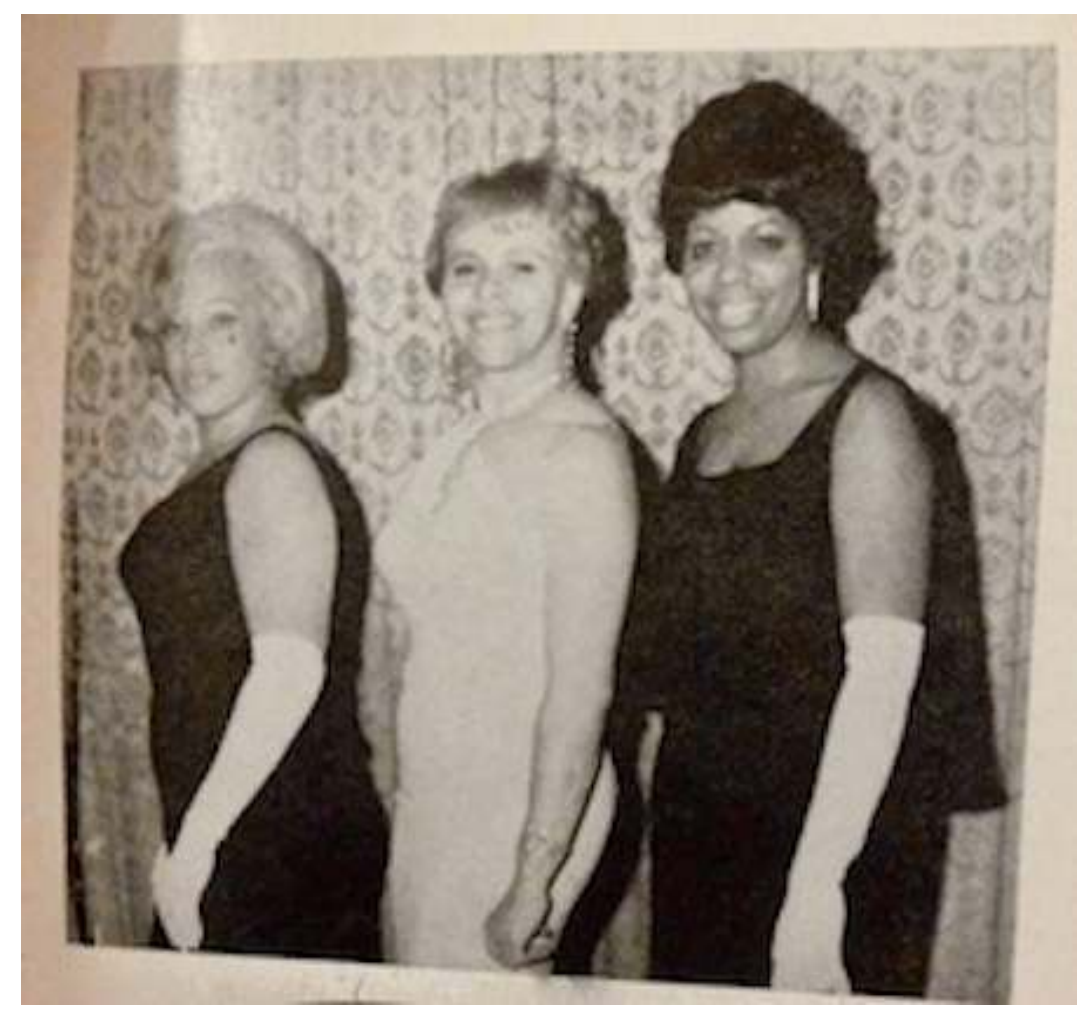

Spring 3100, janvier 1968, p. 48

Enfin, la féminité des policières est parfois mise en avant pour des raisons purement professionnelles, pour les nécessités de l'enquête ou de l'action policière. Ainsi, quand des policiers masculins sont travestis afin de servir d'appâts (les fameux «decoys ») pour arrêter des délinquants s'en prenant spécifiquement aux femmes, des policières interviennent comme garantes de la féminisation de leurs collègues masculins. C'est l'objet d'un reportage approfondi dans le numéro d'octobre 1962 qui fait même la couverture du magazine : 


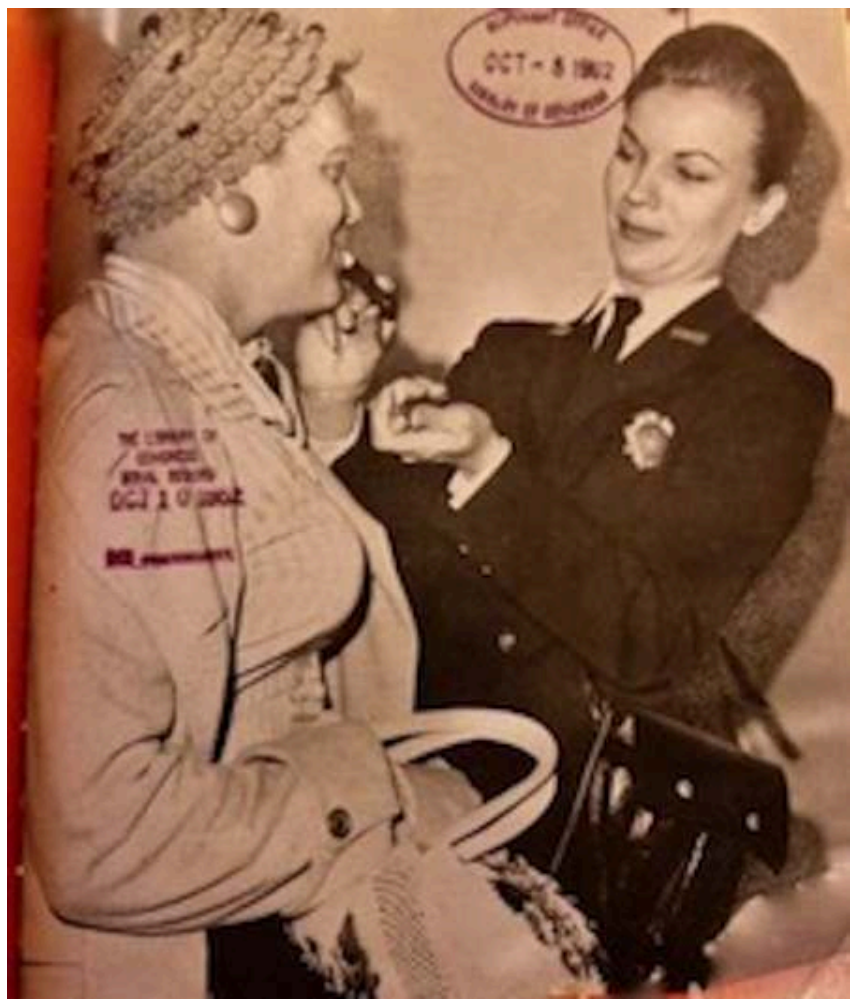

La policière Caryl Collins ajoute la dernière touche de « féminité » au déguisement de ses collègues Spring 3700, octobre 1962, couverture

31 L'accent mis sur la spectaculaire féminisation des policiers masculins est d'autant plus singulier que ce rôle d'appâts est parfois joué depuis les années 1920 par des policières elles-mêmes ${ }^{10}$.

\section{Débattre en images des femmes dans le NYPD : une progressive normalisation du regard masculin?}

Les dessins de presse, parus dans Spring 3100, constituent une source intéressante car ils donnent à voir une perception moins institutionnelle et plus relâchée. On peut, dès lors, supposer que malgré son statut fictionnel et son évolution vers une plus grande codification au cours du XXe siècle, ce registre de l'expression policière renseigne sur la façon dont le travail des policières est perçu par leurs collègues masculins.

\subsection{Entre absence et fantasme : mais pourquoi dessiner des policières?}

Peu après sa création en 1933, Spring 3100 ouvre l'accès à des formes d'expression ludique à certains de ses lecteurs. La rubrique Kop Komiks est alimentée par les dessins envoyés chaque mois à la rédaction par des membres volontaires du département. Ceux-ci évoquent très rarement leurs collègues féminines. Les policières, qui ne composent qu'une extrême minorité des effectifs (moins de $1 \%$ ), ne semblent pas faire partie de l'univers quotidien de leurs collègues masculins. Les thèmes de prédilection 
de ces dessinateurs amateurs renvoient plutôt à l'univers hiérarchique - notamment la relation des agents avec leurs supérieurs directs, les sergents - d'où les femmes sont absentes ${ }^{11}$, à la fonction perçue comme la plus emblématique du travail policier, la patrouille ou encore à la conciliation de la vie professionnelle et de la vie domestique. Ainsi, dans les années 1930, ne trouve-t-on quasiment aucun dessin de femmes au travail, à l'exception du dessin suivant, qui exprime l'incongruité que constitue visiblement pour son auteur la présence des femmes dans l'institution :

Dessin $n^{\circ} 3$.

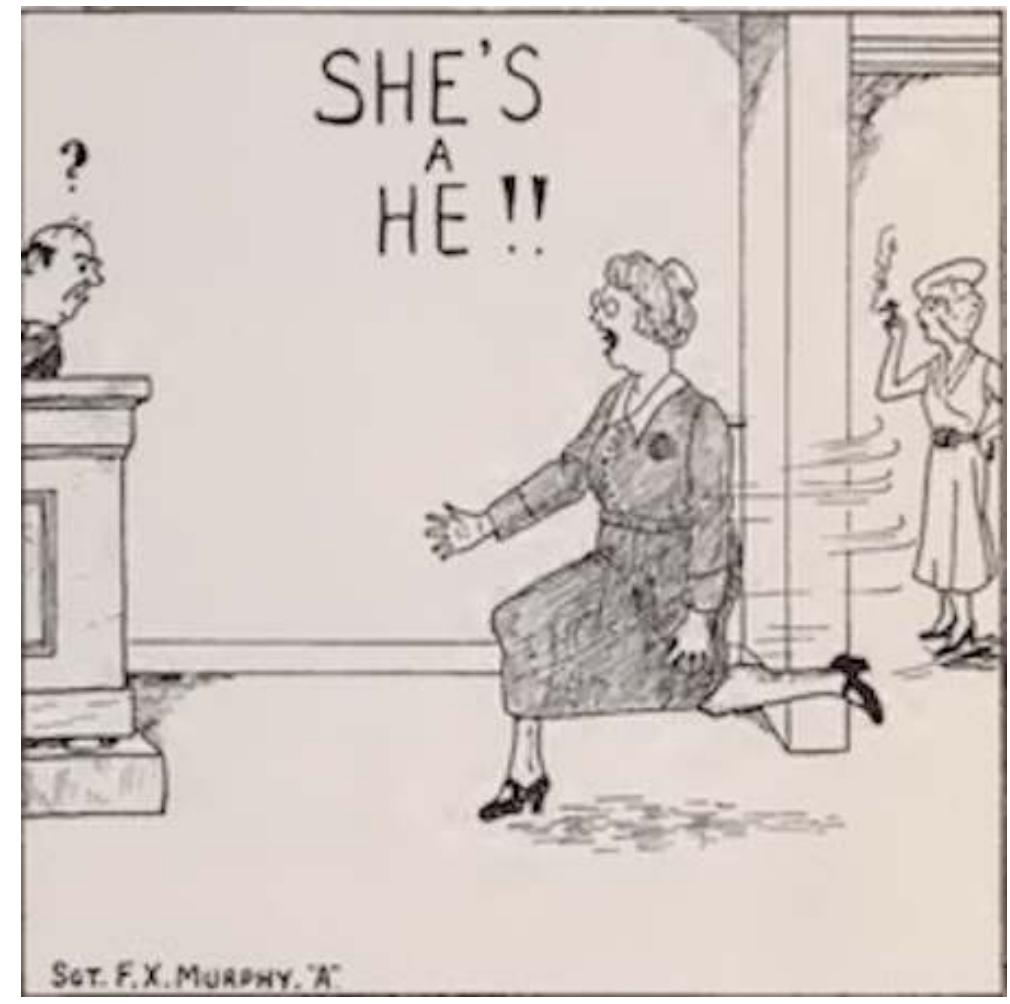

Sergent Murphy

Spring 3100 , octobre 1934, p. 11

Le sergent Murphy, qui fait partie des contributeurs réguliers, présente une policière dans son activité quotidienne (la fouille des prévenus féminins) mais sous l'emprise de la panique à la suite de la découverte d'un travesti. Cette réaction jette un doute sur la capacité de la policière, voire de l'ensemble des policières, à maîtriser leur relation avec le sexe fort, même travesti, et à assurer leurs fonctions dans l'institution. De fait, les dessins de Murphy ou d'autres contributeurs mettant en scène des policiers masculins face à d'autres formes supposées de transgression (des homosexuels masculins par exemple) font plutôt apparaître une indifférence ironique ou une hostilité placide. Les dessins des années 1930 inscrivent ainsi l'identité professionnelle dans un système de représentations profondément genrées, associant étroitement identité masculine et identité policière d'un côté, hétérosexualité et virilité de l'autre. Cette masculinité est, par ailleurs, polymorphe et en rien réduite à la virilité musclée : souvent débonnaire, parfois relâchée, toujours tranquille ${ }^{12}$. Cependant, cette production visuelle ne remet aucunement en cause l'évidence de la domination des policiers masculins sur les femmes (sauf à la maison sous la forme d'une inversion classique des univers 
professionnels et privés), y compris quand celles-ci sont des collègues, ou sur les individus considérés comme déviants. Une trentaine d'années plus tard, les souvenirs de Kathy Burke, entrée dans la police à la fin des années 1960, font écho au dessin $n^{\circ} 3$ du sergent Murphy. La pratique, en forme de bizutage, consistant à réserver à des policières débutantes la fouille d'hommes travestis a, semble-t-il, persisté au sein du NYPD (Burke, 2006, 58-59).

De fait, après la Seconde Guerre mondiale, les dessins continuent à creuser le sillon de l'adéquation entre identité professionnelle et identité de genre. Certes, la production graphique, d'abord espace d'expression libre, s'est codifiée : la rubrique Kop Komics disparaît en janvier 1950 et la fourniture de dessins n'est progressivement plus assurée que par deux dessinateurs, mais toujours policiers, Dan Malone et Stanley Sherry. Après des années de tâtonnements éditoriaux pendant lesquelles les dessins humoristiques disparaissent temporairement et l'essai de différentes formules plus ou moins durables, Malone, qui contribue depuis janvier 1954, obtient en janvier 1958 une rubrique permanente, «Pillow to Post» tandis que Sherry illustre plus occasionnellement la revue. De leur côté, les femmes, qui ne disposaient auparavant d'aucun moyen d'expression ludique dans la revue (seules les directrices de la police féminine pouvaient s'exprimer sur des sujets sérieux) accèdent à une parole plus libre dans la description de leur place dans l'institution. Dans la rubrique «Lookin' them over ", elles décrivent parfois la vie de la section de la police féminine de manière amusée et usent au besoin de provocation mesurée, notamment quand les femmes accèdent aux grades supérieurs. Elles n'accèdent toutefois pas à la production de dessins humoristiques. Aussi les hommes continuent-ils de livrer leur version d'une culture professionnelle masculine. L'évocation de la présence des femmes dans le NYPD reste ainsi au mieux anecdotique, voire fantasmatique.

Entre 1958 et 1963, Malone ne consacre aucun dessin aux femmes policières dans sa rubrique "Pillow to Post ». La représentation le plus proche met en scène un « appât » masculin déguisé en femme :

Dessin $n^{\circ} 4$

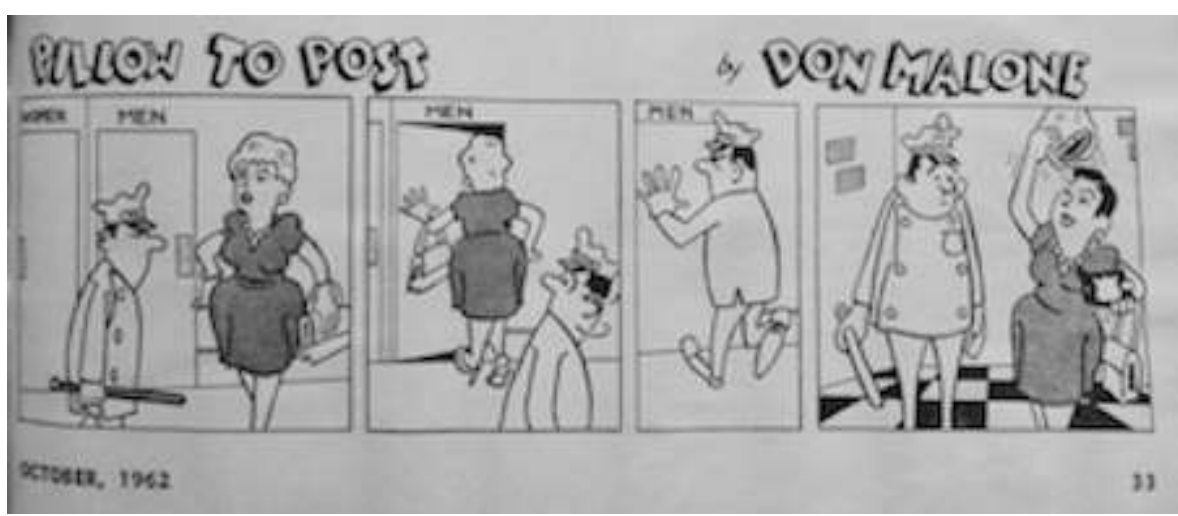

Don Malone

Spring 3700, octobre 1962, p. 33

Malone n'évoque la présence des femmes dans l'institution qu'à travers la figure des surveillantes de traversée piétonne (un dessin en 1961, un autre en 1962). Et encore ces dessins se contentent-ils de reproduire un stéréotype féminin : la discussion animée entre deux femmes - l'une passante, l'autre surveillante - conduit un policier masculin 
à s'éloigner prudemment. L'essence féminine l'emporte sur l'uniforme: les deux femmes représentées (une passante et une assistante) sont très similaires, qu'elles agissent comme individus privés ou au nom de la ville.

Dessin $n^{\circ} 5$

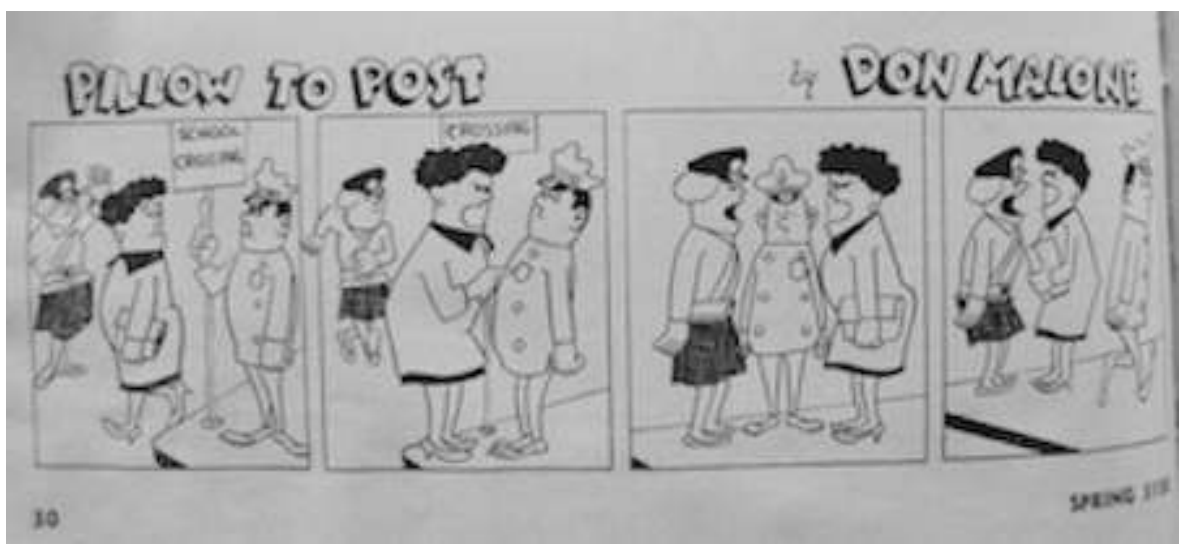

Dan Malone

Spring 3700, mai 1962, p. 30

La figure du policier débonnaire, presque naïf, gentil condensé d'humanité ordinaire qui fait partie des figures récurrentes de Malone - contraste avec l'essence d'une féminité hystérisante, comme le confirme un autre dessin de Malone publié deux ans plus tard:

Dessin $n^{\circ} 6$

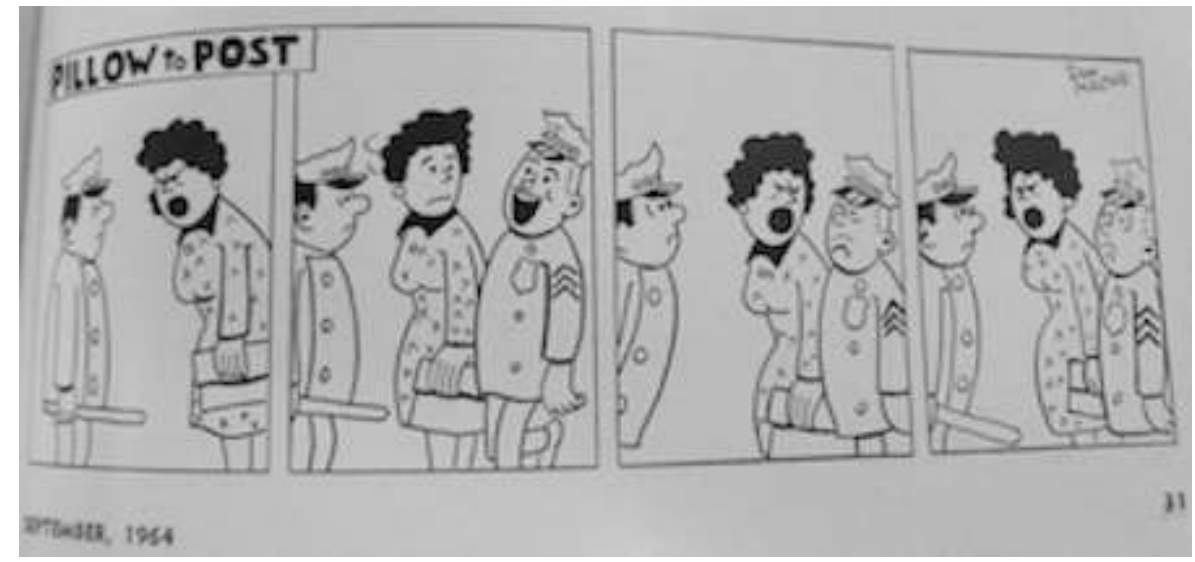

Dan Malone

Spring 3100, septembre 1964, p. 31

Finalement, les seules évocations par Malone du travail policier féminin avant 1964 passent-elles par le rituel, hors rubrique, du dessin de Noël montrant les actions caritatives du NYPD à destination des enfants à cette période de l'année : 
Dessins $n^{\circ} 7$ et 8 .

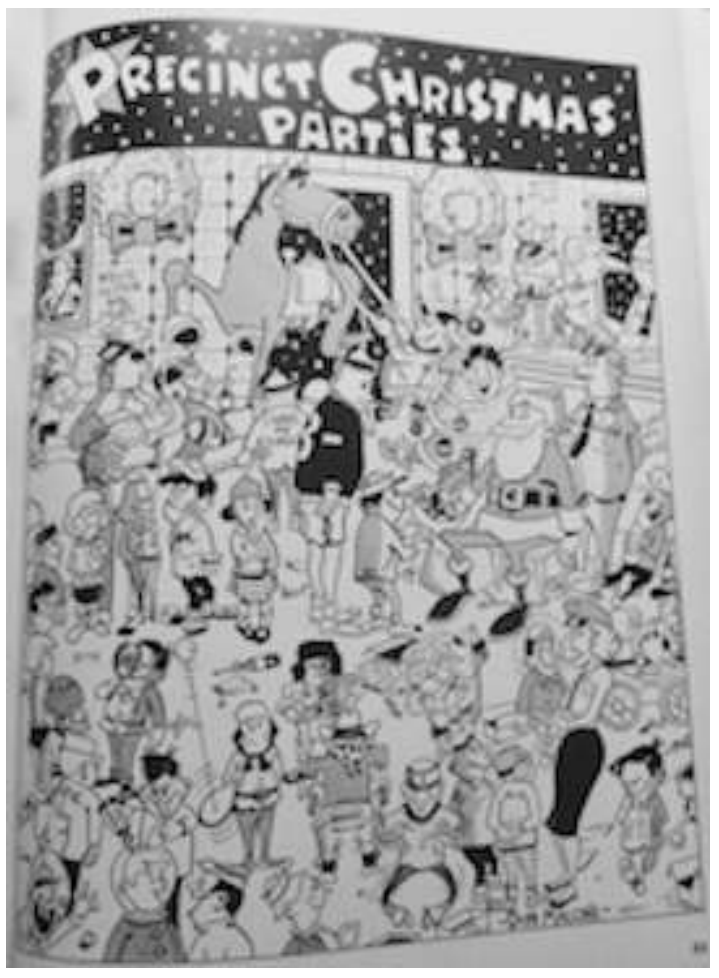

Dessin $n^{\circ} 8$.

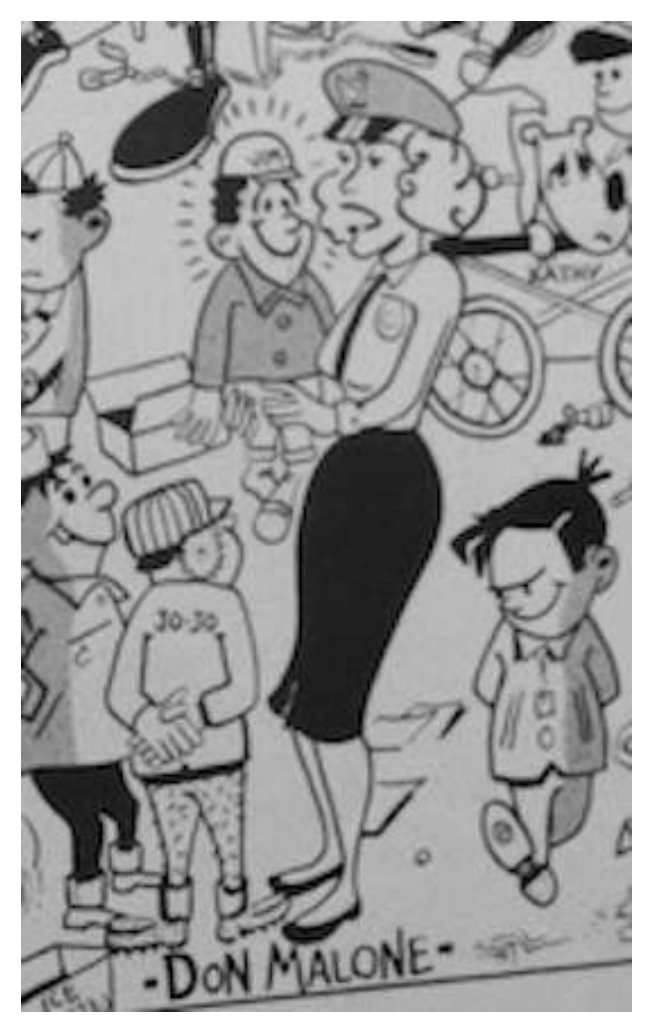

Dan Malone

Décembre 1960, p. 23, vue générale et gros-plan 
L'évocation est minimale (la policière est perdue au milieu d'une profusion de détails graphiques) et conventionnelle (quoique stylisée et sexualisée, elle s'occupe des enfants ${ }^{13}$. À travers le rituel du dessin de Noël, Sherry donne, de son côté, à voir une expression purement fantasmatique de la présence des femmes dans l'institution, celle de pin-up dans un uniforme érotisé :

\section{Dessin $n^{\circ} 9$.}

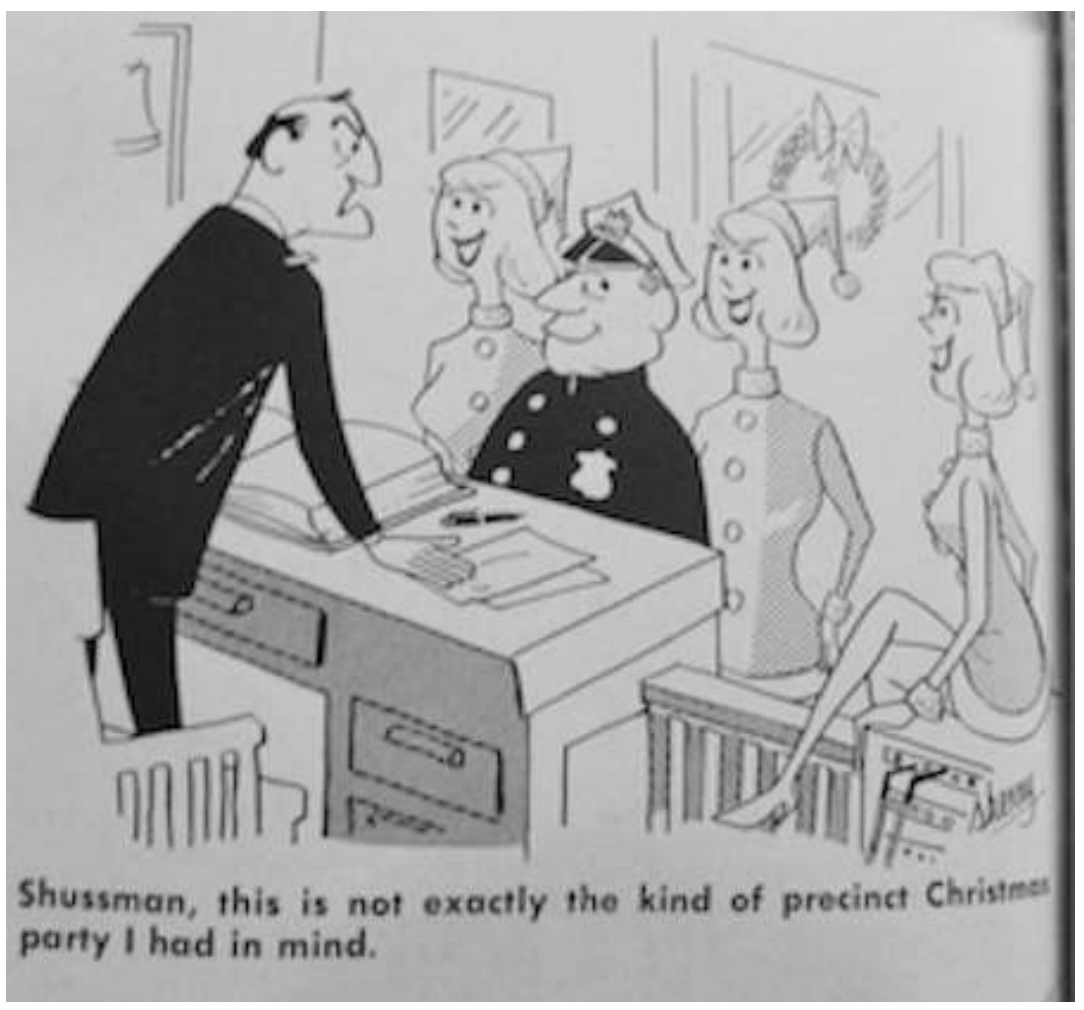

Stanley Sherry

Spring 3100, décembre 1962, p. 34

C'est pourtant au sein de ce cadre d'expression apparemment peu favorable à l'évocation du changement que s'opère une forme de discussion des transformations apportées par les années 1960.

\subsection{La femme sergent : représenter, anticiper ou accepter le changement?}

42 Tout change, en effet, à partir de 1964. Le travail féminin qui semblait si anecdotique fait l'objet d'un soudain investissement graphique: Malone consacre 14 dessins entre 1964 et 1972 aux policières, contre zéro entre 1958 et 1963. Ces dessins apparaissent comme un espace de discussion, de réaction et d'anticipation face à la féminisation des grades supérieurs. La féminisation du métier est abordée à travers les thèmes qui structurent l'humour policier dans les dessins de presse: l'économie du couple, les relations de séduction entre les sexes, la question disciplinaire. Un seul type de travail, pensé comme emblématique de ce qu'est le travail policier, est véritablement présent : le travail dans la rue en patrouille avec ce qu'il implique de relations avec les 
supérieurs hiérarchiques directs. Le problème est donc bien la possibilité d'un commandement exercé par les femmes sur les hommes.

Dan Malone évoque le changement avant même qu'il n'intervienne officiellement dans deux dessins parus en 1964. Le premier dessin paraît, en effet, en mars 1964, alors que les premières candidates ne passent l'examen pour le grade de sergent qu'en avril $1964^{14}$ et que les premières promotions ne se produisent que l'année suivante, en mars 1965. Les tribunaux ont, cependant, déjà donné gain de cause à Felicia Shpritzer.

Dessin $n^{\circ} 10$

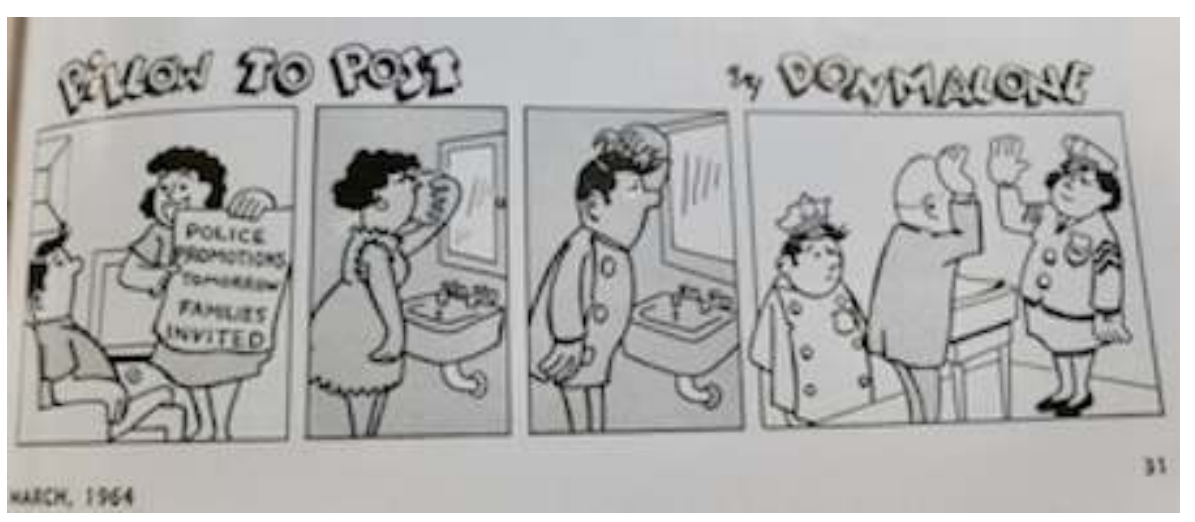

Dan Malone

Spring 3100, Mars 1964, p. 31

La nouvelle est discutée dans le cadre de l'économie du couple. Avec une ironie douce et bienveillante, Dan Malone joue avec l'effet de surprise en donnant à voir la possibilité que des femmes passent devant des hommes dans la promotion au grade de sergent. On peut penser qu'à travers cette anticipation, Malone poursuit plusieurs objectifs : alerter les esprits, évoquer le changement à venir sous un angle intime et personnel tout en conservant un registre conventionnel (l'économie du couple). Le deuxième dessin paru en décembre 1964 aborde une autre question, abondamment traitée ensuite : les relations de séduction entre collègues - vues du côté masculin.

Dessin $n^{\circ} 11$

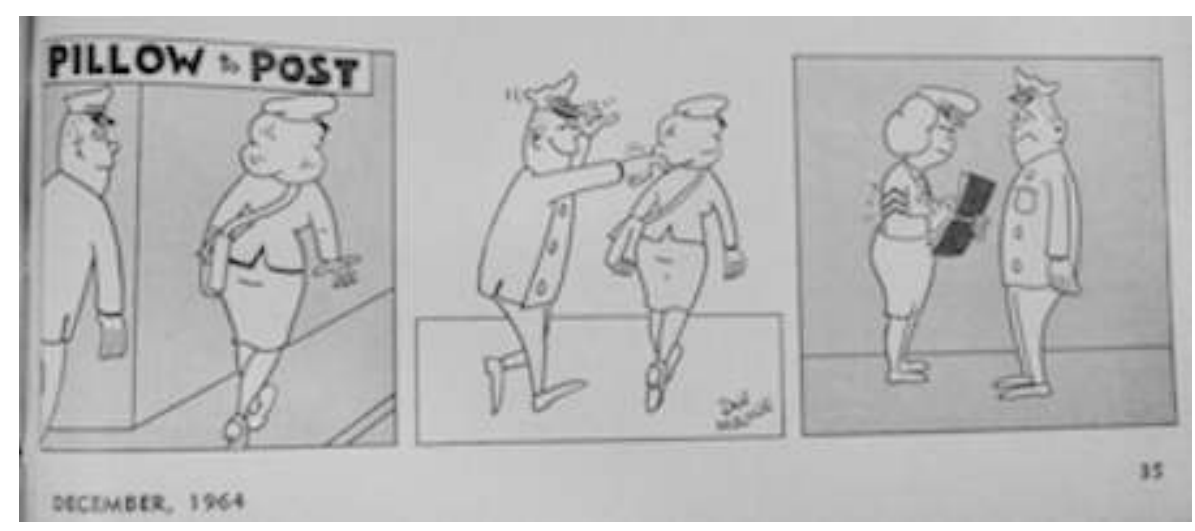

Dan Malone

Spring 3100, Décembre 1964, p. 35 
Le dessinateur, jouant sur un double retournement, évoque le pouvoir disciplinaire que pourraient exercer les femmes au sein du département. Une policière jeune, blonde et ayant attiré l'attention d'un jeune policier en patrouille, révèle en se retournant ses galons rutilants (trois chevrons signalent son grade de sergent) et sa position d'autorité. Il s'agit cette fois d'une anticipation à double titre. Non seulement il n'y a pas encore alors de femmes exerçant effectivement le grade de sergent - Shpritzer et Schimmel ne sont promues qu'en mars 1965 - mais, tout au long de la procédure judiciaire qu'elle a initiée, Felicia Schpritzer a défendu dans la presse l'idée que l'accession à des fonctions d'autorité ouvrirait aux policières des positions d'autorité sur des collègues féminines mais en aucun cas sur des hommes. D'ailleurs, en mars 1965, il est spécifié que Schpritzer et Schimmel rempliront leur fonction uniquement au sein du Bureau des femmes policières et qu'elles n'auront pas de pouvoir disciplinaire sur leurs collègues masculins ${ }^{15}$.

Après 1965 - et les promotions effectives des femmes dans la hiérarchie -, Malone use encore de l'effet de surprise pour alerter ses collègues masculins sur le caractère inédit de la situation: en patrouille, les policiers peuvent s'attendre à voir en toute femme rencontrée dans la rue une collègue potentielle, voire une supérieure. C'est la remise en cause d'une dimension souvent mise en scène dans les dessins de presse de la revue depuis son origine : le pouvoir d'un policier sur sa zone de patrouille est un pouvoir sur les individus, et singulièrement un pouvoir des hommes sur des femmes, celui d'imposer - abusivement ou non - son regard, voire d'engager la conversation en position d'autorité ou en bénéficiant du prestige de l'uniforme :

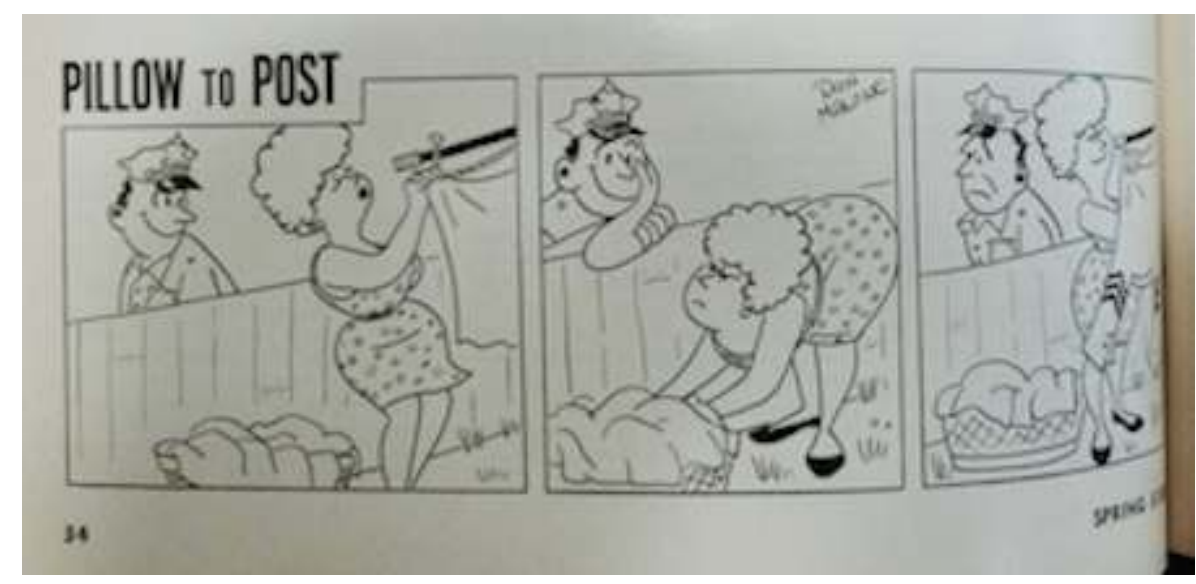

Dan Malone

Spring 3100, juillet-août 1966, p. 34 


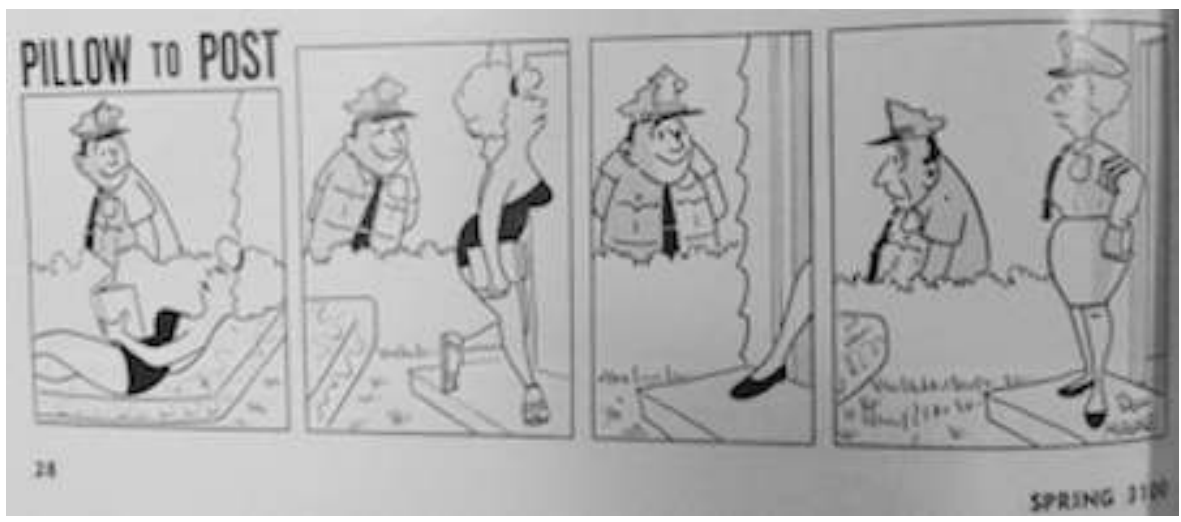

Dan Malone

Spring 3700, octobre 1967, p. 28

Ces dessins n'apportent pas seulement, comme l'écrit Andrew T. Darien, un soulagement comique - notamment par la sexualisation du corps des femmes sergents - aux policiers rétifs au changement (Darien, 2013, 110-113). Ils fournissent également un mode d'emploi des relations entre les sexes, à partir du point de vue masculin et misogyne qui est probablement celui de ses lecteurs. Considérée dans son ensemble la production de Malone suggère que, pour minimiser les déconvenues, les policiers doivent apprendre, dans leurs relations professionnelles avec des policières en uniforme, à dissocier sexe, genre, ethos professionnel et vie privée. Renoncer à un univers professionnel unisexe conduit nécessairement à opérer une sorte de dédoublement psychologique et corporel :

Dessin $n^{\circ} 14$

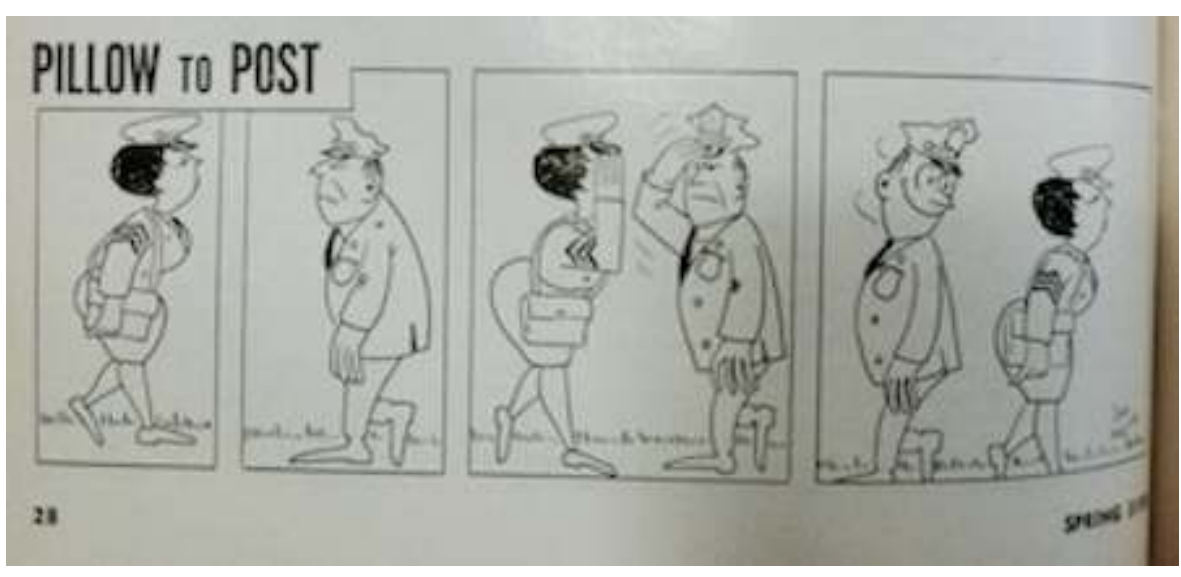

Dan Malone

Spring 3700, mai 1966, p. 28 


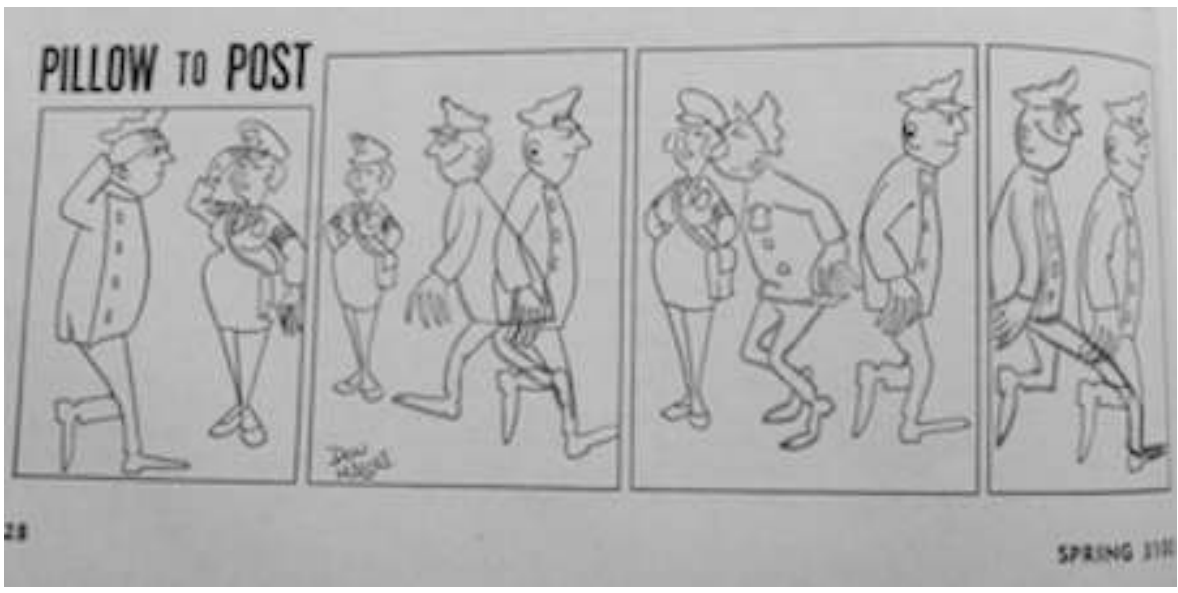

Dan Malone

Spring 3100, avril 1969, p. 28

Dans une profession de plus en mixte, les policiers doivent produire des performances de genre contrôlées, maîtrisées : savoir à quel moment observer les femmes policières et leurs attributs sexuels - quand elles sont de dos ! - (dessin $\left.n^{\circ} 14\right)$ ou - plus sûrement - n'avoir d'interactions avec elles que mentales (dessin $n^{\circ} 15$, trois ans plus tard). Le dessin $n^{\circ} 16$ indique enfin comment traiter la frustration et la perte de pouvoir engendrées par la cohabitation des sexes dans l'institution. Là encore, Malone convoque une rhétorique professionnelle habituelle: imaginer, comme les policiers le font déjà avec les sergents masculins, la femme sergent en figure d'autorité déplaisante - dès lors physiquement et moralement peu désirable :

\section{Dessin $n^{\circ} 16$.}

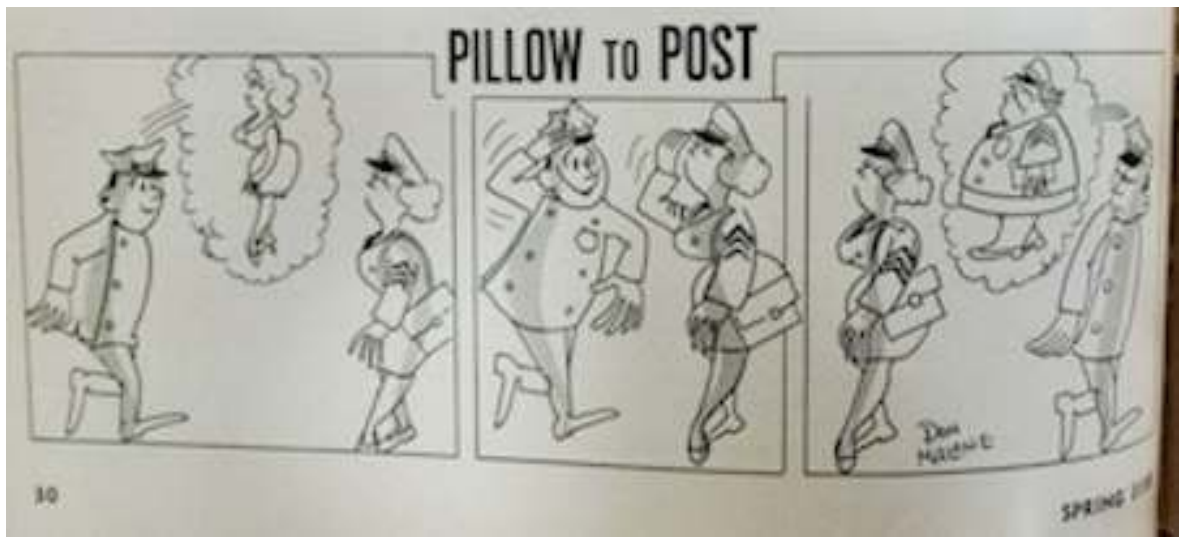

Dan Malone

Spring 3700, Octobre 1966, p. 30

En 1970, Malone livre enfin sa version d'une pleine acceptation des compétences policières de ses collègues féminines : 
Dessin $n^{\circ} 17$.

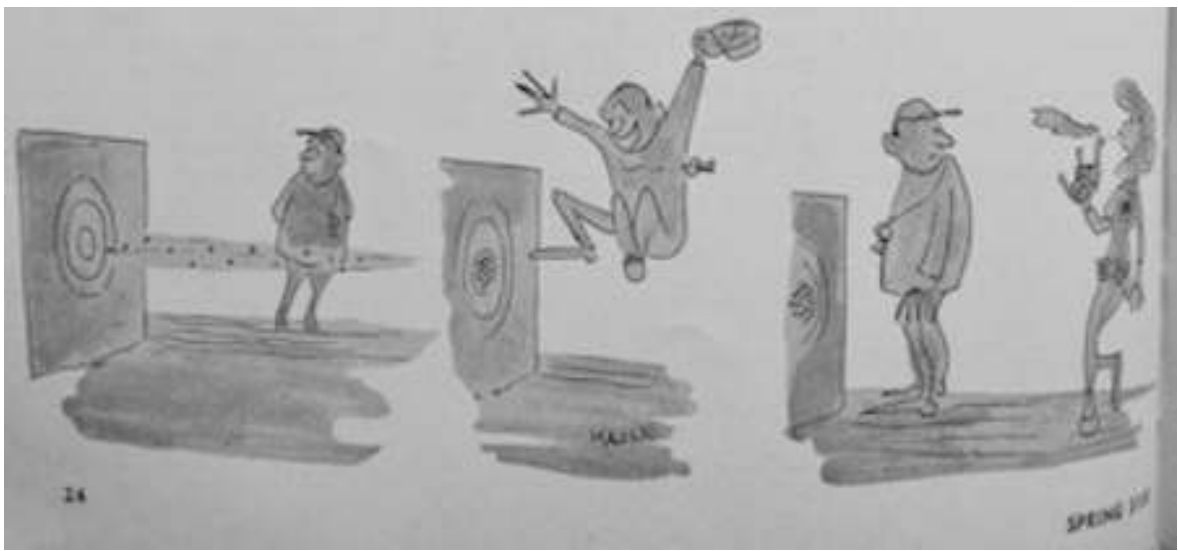

Dan Malone

Spring 3700, Mars 1970, p. 24

50 Même si le dessin adopte la structure conventionnelle de la révélation, la représentation d'une policière sachant tirer ne saurait surprendre les lecteurs de la revue, familiers des reportages montrant des stands de tir mixtes ou célébrant l'équipe féminine de tir du NYPD. Plus singulier est l'héroïsation de cette policière féminine. Évoquant une héroïne de western, une Calamity Jane, moderne et érotisée, celle-ci fait également figure de policière accomplie. L'autre dessinateur de Spring 3100, Stanley Sherry use, souvent, d'un registre plus explicitement misogyne que celui de Malone. Mais en 1968, il livre sa version d'une acceptabilité de la présence des femmes dans l'institution policière : 


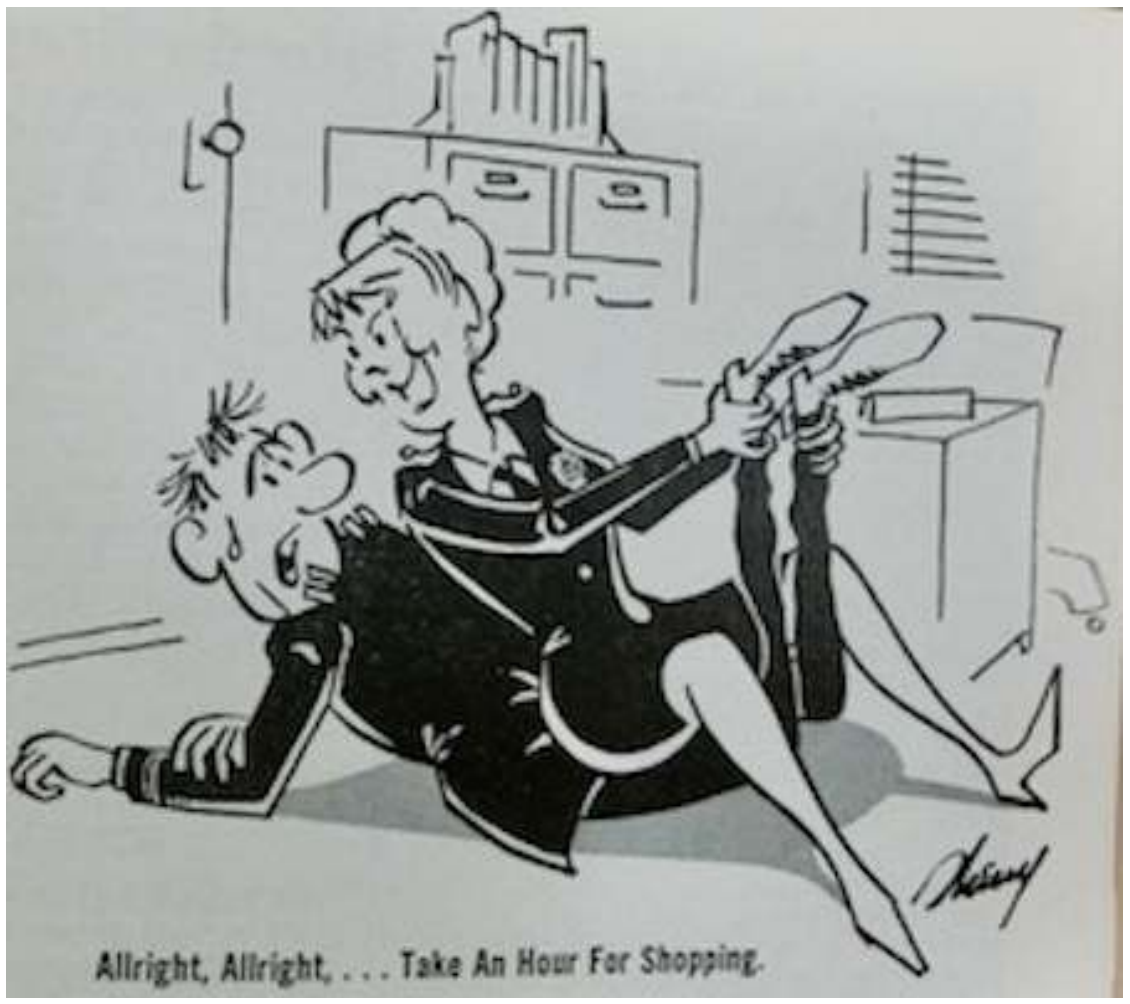

Stanley Sherry

Spring 3100, avril 1968, p. 31

51 Certes, Sherry joue toujours à plein du stéréotype. Tout en étant policière, son personnage reste une fervente adepte du shopping. Mais elle sait imposer ses vues grâce à une maitrise de l'affrontement physique probablement acquise à l'école de police. Rien n'indique cependant que les dessins de Malone et Sherry aient été efficaces et que la position ainsi défendue était partagée par l'ensemble des lecteurs.

\subsection{Débats imagés sur la présence des femmes dans l'institution}

On trouve dans Spring 3100 des traces visuelles de la perception par les hommes du NYPD du travail des femmes policières. Dans sa fonction de libre expression visuelle, la rubrique "Kop Komics» a été remplacée par une nouvelle rubrique, "Cop Captions». Celle-ci donne, à partir d'octobre 1962, la possibilité à des policiers ordinaires d'exprimer leur opinion de façon amusée, en proposant une légende à une photographie choisie par l'équipe éditoriale. En juin 1963, alors que Felicia Shpritzer est sur le point de gagner sa procédure judiciaire contre la ville, un agent ironise sur le recrutement de policières féminines: 
«Cop Caption » $n^{\circ} 1$

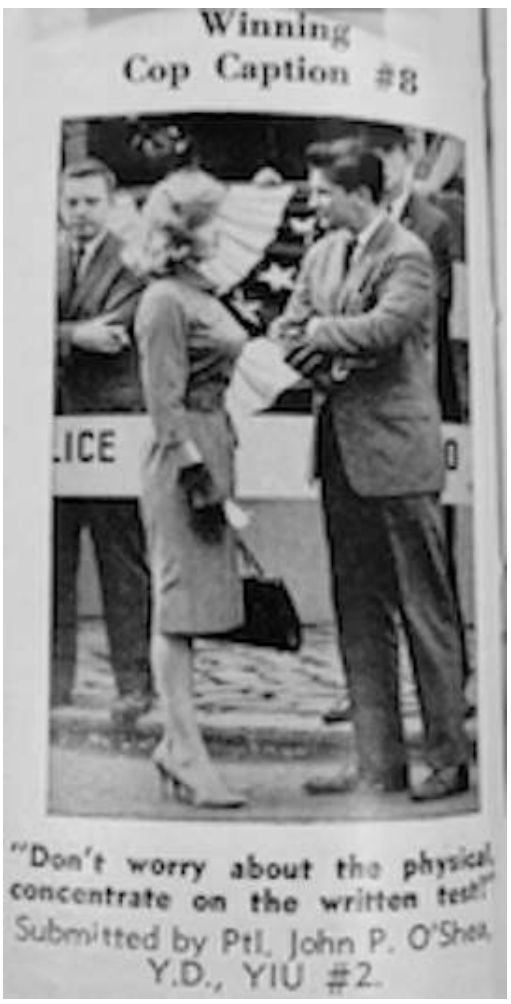

Spring 3700, Juin 1963, p. 48

Une fois encore la question de la présence des femmes est ramenée à leur attractivité sexuelle. Celle-ci dispenserait la supposée candidate de travailler la partie des examens d'entrée destinée à mesurer la forme physique des candidat(e)s, au contraire de la partie intellectuelle jugée beaucoup plus difficile pour une femme. Après 1965 et la promotion de femmes à des positions de commandement, les avis restent partagés : 
«Cop Captions » $\mathrm{n}^{\circ} 2$ et $\mathrm{n}^{\circ} 3$.

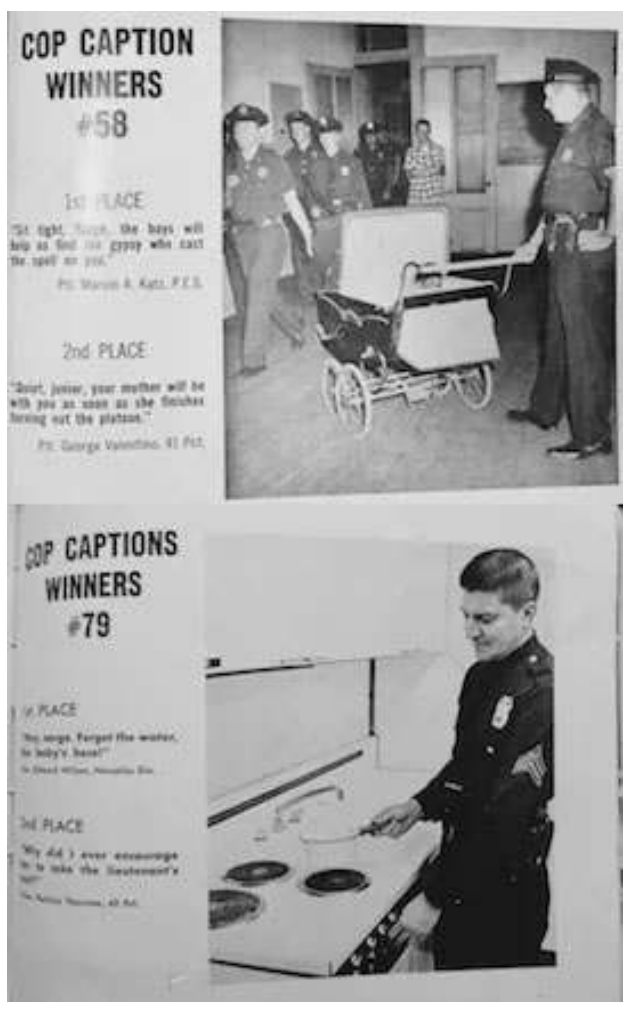

Spring 3100, mars 1968, p. 49 et mars 1970, p. 49

54 Les deux légendes qui ont obtenu le 2ème prix tirent le sens des photographies vers la question de la présence des femmes dans l'institution et évoquent les manifestations d'ambivalence face aux changements en cours dans l'institution. "Qui va garder les enfants?", semble s'interroger l'agent George Valentino en suggérant la figure d'une femme sergent occupée à donner ses instructions, lors de l'appel précédent la patrouille, aux agents sous son autorité pendant que son mari, lui aussi sergent, est contraint à l'inactivité car il doit s'occuper de leur bébé ${ }^{16}$. La policière Patricia Thornton, commentant l'image d'un sergent faisant bouillir de l'eau, se moque quant à elle des réticences de ses collègues masculins à voir leur épouse les dépasser dans la hiérarchie et leur abandonner une partie des tâches domestiques ${ }^{17}$. Il est, sans doute, difficile d'apporter une interprétation tranchée au sens donné par les auteurs à des interventions aussi ramassées ${ }^{18}$. On peut noter, cependant, que le débat passe par un commentaire sur les images et qu'il est contradictoire même s'il n'évoque le travail féminin qu'en creux, à travers la figure de l'absente. La première image ("Cop caption » $n^{\circ} 2$ ) inverse la relation argumentative mobilisée sur les cartes postales étudiées par Juliette Rennes : ce n'est pas l'argument verbal de l'incompatibilité entre les devoirs maternels ou domestiques qui trouve une expression visuelle comme sur les cartes postales (Rennes, 2013b, 180-189) mais la vision d'une image qui suscite un commentaire ironique ramassant un discours constitué ${ }^{19}$. La seconde image ( $C_{o p}$ caption " $\mathrm{n}^{\circ} 3$ ) montre que des images au motif proche peuvent être investies de significations fort différentes, voire inversées, selon leur contexte de réception. La charge critique associée à la vision d'un homme occupé à des tâches domestiques est renversée si on la compare aux cartes postales hostiles au droit de vote des femmes au début $\mathrm{du}$ XXe siècle étudiées par Catherine $\mathrm{H}$. Palczewski : l'évocation du ridicule ne 
sert pas à exprimer le danger d'une perte de virilité (Palczewski, 2005, 367-381), mais au contraire à enjoindre les hommes à s'adapter à des contraintes nouvelles, somme toute relativement dérisoires.

La rubrique "Memorandoms ", apparue en 1969, est un autre forum d'expression pour les membres du département, dans lequel l'aspect textuel et argumenté des interventions prime. Possibilité est donnée aux individus interrogés de développer en quatre ou cinq phrases leur point de vue et au besoin de le nuancer. Mais les témoignages, accompagnés d'une photographie en uniforme, se font nécessairement à visage ouvert devant la communauté policière.

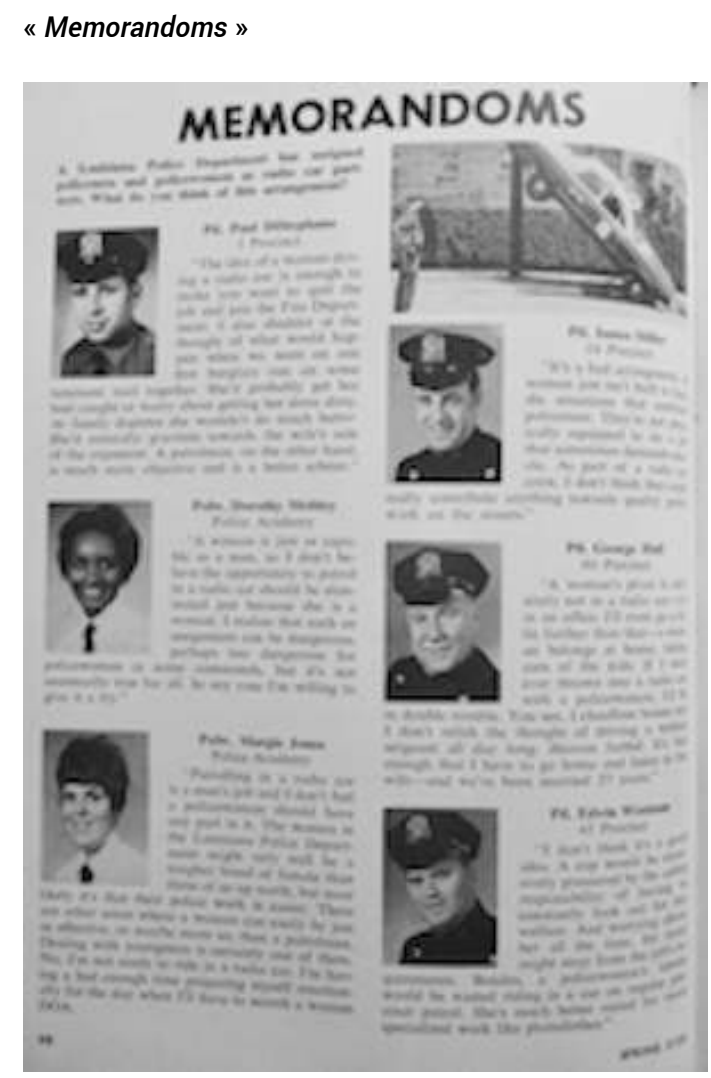

Spring 3100, décembre 1969, p. 48

Signe de débats en cours, le numéro de décembre 1968 invite policiers et policières à donner leur avis non sur une transformation déjà engagée, mais sur une réforme possible, la pratique, expérimentée ailleurs dans le pays, consistant à affecter ensemble policiers et policières dans les voitures de patrouille ${ }^{20}$. Cette mini-consultation ne présage en rien de la mise en œuvre dans le NYPD de cette mesure quatre ans plus tard, en 1973. En 1968, les positions sont très inégalement réparties : quatre policiers en activité livrent un avis unanimement - et pour certains vivement - négatif tandis que les deux femmes interrogées sont encore à l'école de police et divisées sur la question. Surtout l'habillage visuel confirme le parti-pris éditorial de la revue : la photographie d'une voiture de patrouille spectaculairement accidentée sous l'œil incrédule d'un policier accompagne les témoignages, laissant ainsi entendre que seule une femme au volant a pu réussir à placer de façon aussi improbable son véhicule contre un poteau électrique ou un lampadaire. Les policières du NYPD ont-elles protesté vivement contre cette présentation aussi biaisée? Quoi qu'il en soit, cinq mois plus tard, la rubrique 
donne la possibilité à des policières ordinaires d'évoquer les réactions de personnes ordinaires face à la révélation de leur profession (Spring 3100, Mai 1969, p. 48). Cette fois, pas un seul jugement masculin n'est convoqué.

\section{Au-delà du regard masculin : une institution modelée par les femmes et modelant les femmes policières}

57 De quelles ressources disposent les femmes dans un univers professionnel et visuel aussi masculin que celui du NYPD? L'examen d'une production féminine - et non institutionnelle - d'archives visuelles du travail policier féminin permet de fournir un contrepoint et de réévaluer la contribution des femmes à leur expérience de travail.

\subsection{Contrepoint : des archives visuelles produites par une femme}

Réalisé dans la seconde partie des années 1970, le travail de la photographe Jane Hoffer répond à la volonté de remédier à l'anonymat des femmes policières et de briser les stéréotypes. Il s'agit de donner à voir diverses facettes du travail féminin rendant mieux compte de l'expérience réelle et individuelle des femmes dans l'institution policière ${ }^{21}$. De fait, la palette d'activités des femmes policières présentées par Jane Hoffer est bien plus large que celle donnée à voir dans la revue Spring 3100.

La photographe montre des situations de travail très variées : la patrouille - y compris dans des quartiers fortement dégradés et ghettoisés, les affectations dans des services divers dont certains impliquent des compétences spécifiques (police montée, ou services d'urgences impliquant la maîtrise technique d'outils comme les grues ou les engins de désincarcération), l'entraînement sur le pas de tir, le travail de nuit, des moments de relâche et de détente au commissariat tout comme des scènes de vestiaires, le travail de certaines femmes comme instructrices à l'école de police ou dans des services spécialisés, le défilé annuel, les interactions variées des policières avec leurs collègues masculins ou avec la population civile. Cette diversité de tâches inclut des fonctions traditionnellement associées à la masculinité. Surtout, elle implique des situations non seulement où les femmes sont en position de commandement, mais également où elles peuvent faire étalage d'une supériorité physique ou technique. Parmi les policières photographiées, Ann Wilson est formatrice à l'école de police tandis que Helen Knedlehans est agent et instructrice dans une unité de Police-Secours. 
Photographie $n^{\circ} 23$.

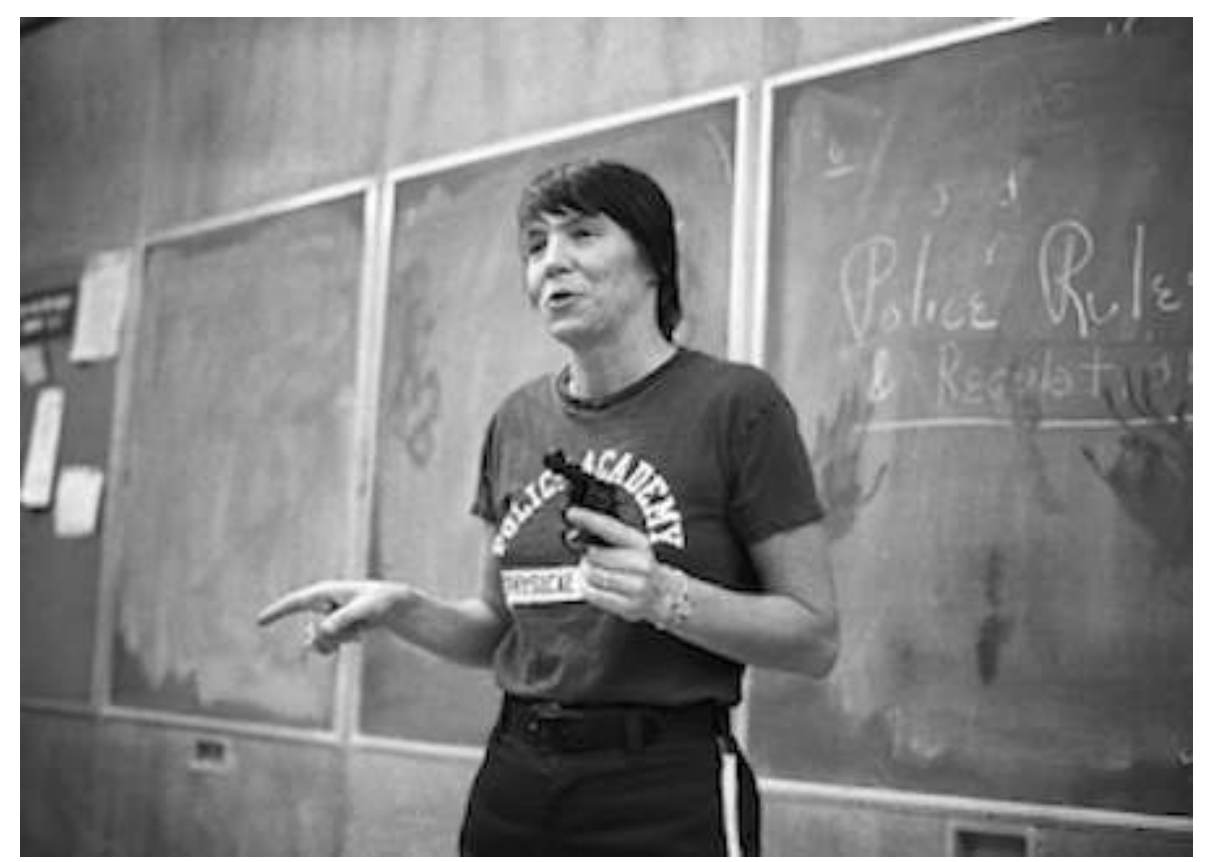

Ann Wilson, instructrice à l'école de police, par Jane Hoffer, circa 1978

(C) Jane Hoffer (source : Jane Hoffer On the Beat Photograph Collection, PR 312, Department of Prints, Photographs, and Architectural Collections, The New-York Historical Society, Box 1, Folder 35)

60 Là encore, ce n'est pas la représentation d'une femme en armes (photo ${ }^{\circ}$ 23) qui apparaît inédite mais sa position d'instructrice, aussi à l'aise sur l'estrade qu'au milieu des recrues féminines comme masculines dont elle vérifie et corrige la posture. Sur d'autres photographies, elle donne des cours de self-défense à des civils hommes ou femmes. 
Photographies $n^{\circ} 24$ et $n^{\circ} 25$.

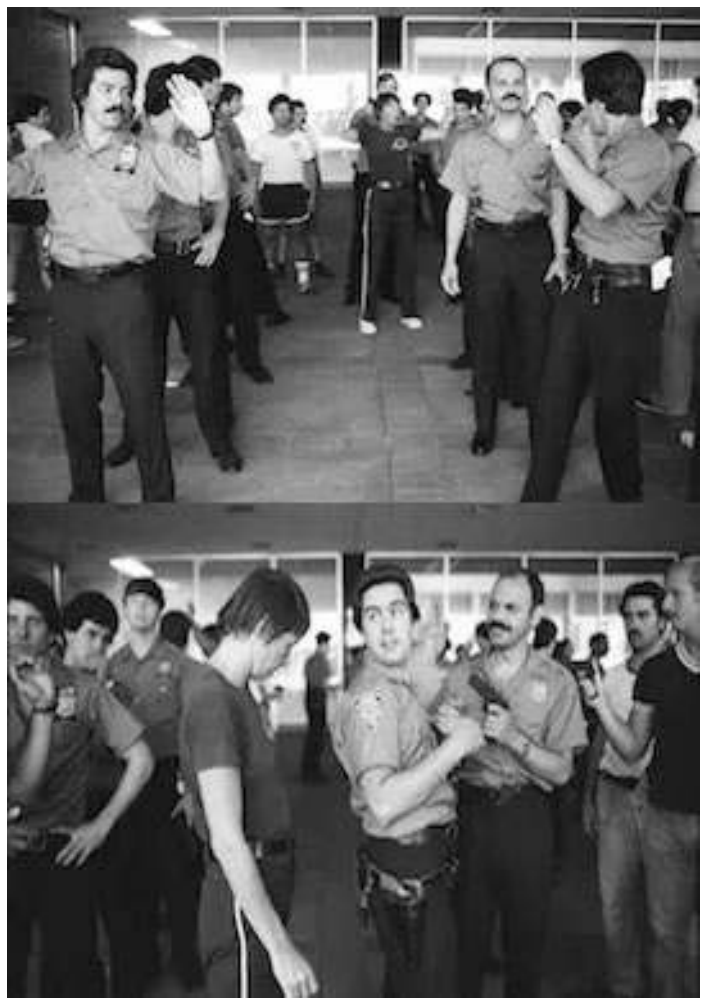

Ann Wilson, par Jane Hoffer, circa 1975-1977

(On the Beat, NYHS, Box 1, Folder 40). ( Jane Hoffer

61 Knedlehans est, quant à elle, montrée à la fois dans des situations de soin (comment soigner un blessé ou mettre au monde un enfant) et dans la maîtrise d'outils imposant associés à la masculinité. 
Photographie $n^{\circ} 26$ et $n^{\circ} 27$.

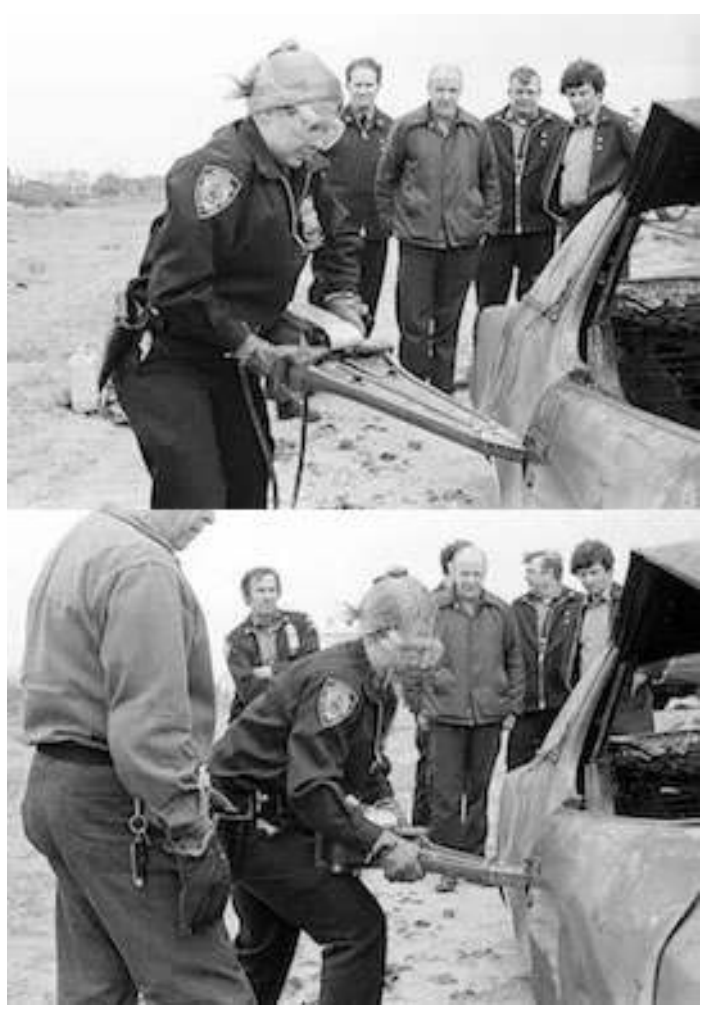

Agent Helen Knedlehans, 1978, par Jane Hoffer

(On the Beat, NYHS, Box 1, Folders 15). ( Jane Hoffer

62 Mais en dehors de l'itinéraire un peu extraordinaire et pionnier de certaines policières qui les met en situation d'autorité - même si Knedlehans confie que la volonté politique a facilité son accession à ces fonctions -, le travail photographique de Jane Hoffer souligne les aspects routiniers du travail des policières et notamment, les interactions quotidiennes avec leurs collègues masculins : 
Photographie $n^{\circ} 28$.

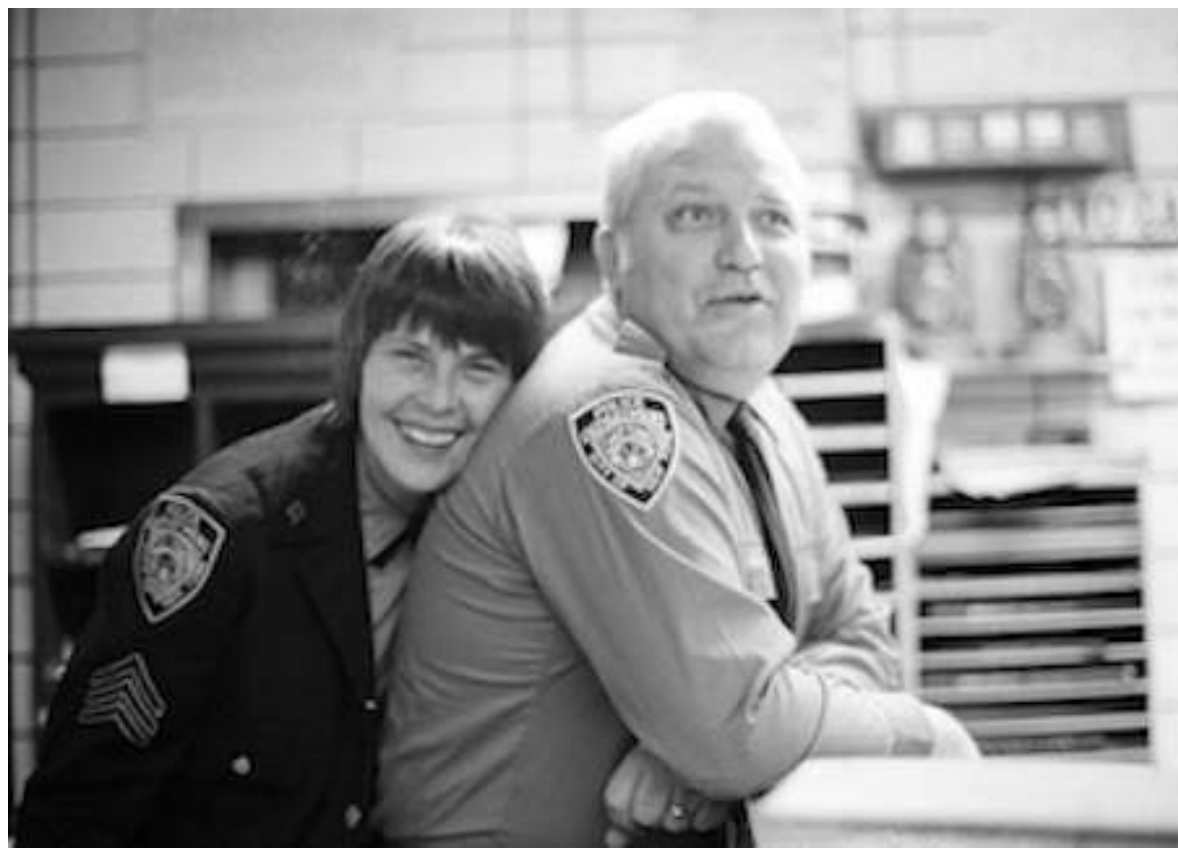

Sergent Joan Pearson, non datée par Jane Hoffer

(On the Beat, NYHS, Box 1, Folders 26 et 20). ( ) Jane Hoffer

Photographies $n^{\circ} 29,30$ et 31 .

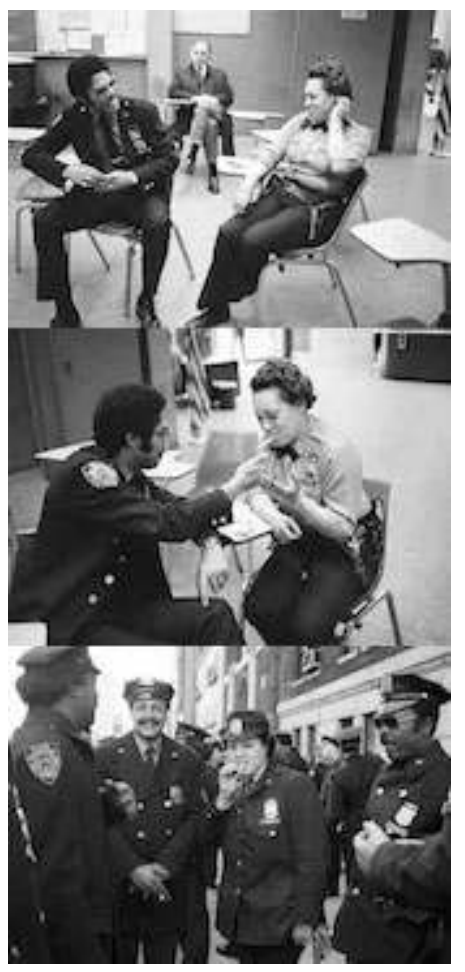

Sergent Barbara Collins, circa 1975, par Jane Hoffer

(On the Beat, NYHS, Box 1, Folders 7 et 40). (CJane Hoffer 


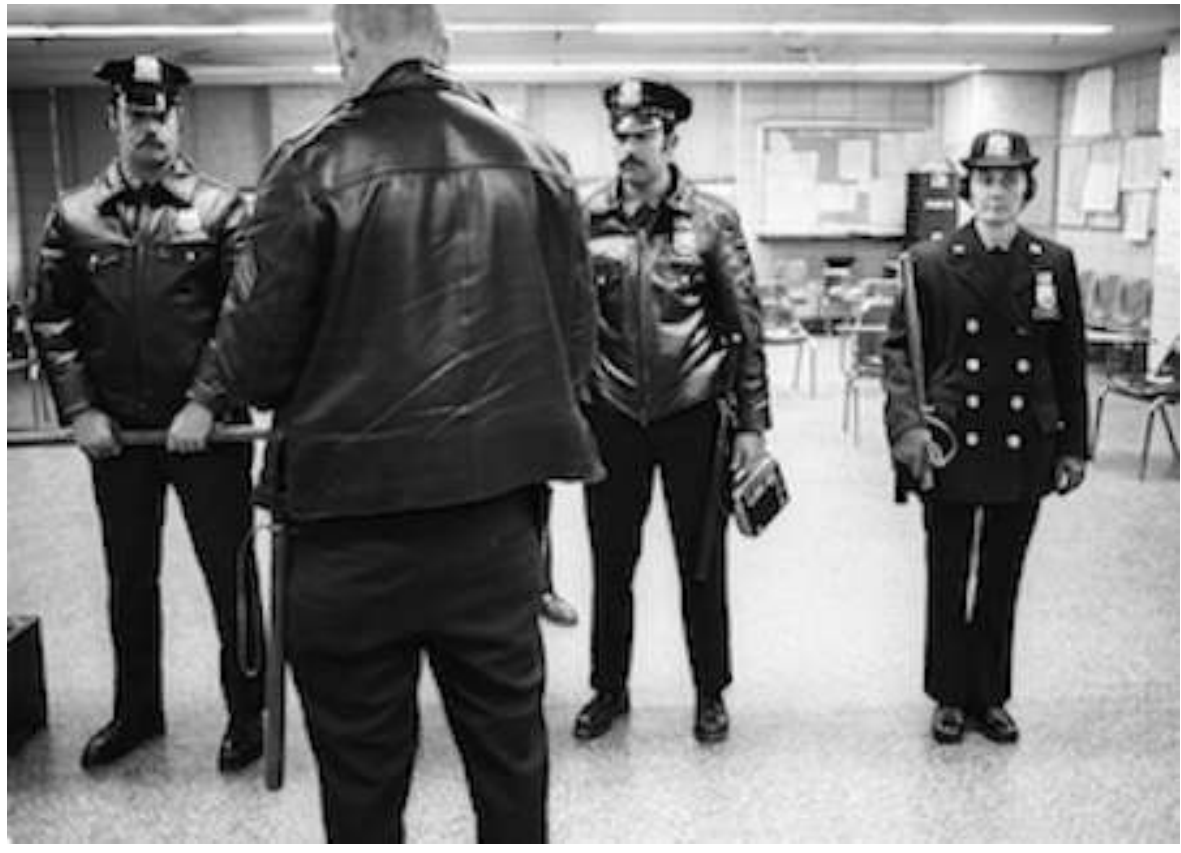

Agent Mary Hartmann, par Jane Hoffer, non datée

(On the Beat, NYHS, Box 1, Folder 12). (CJane Hoffer

\section{Photographie $n^{\circ} 33$}

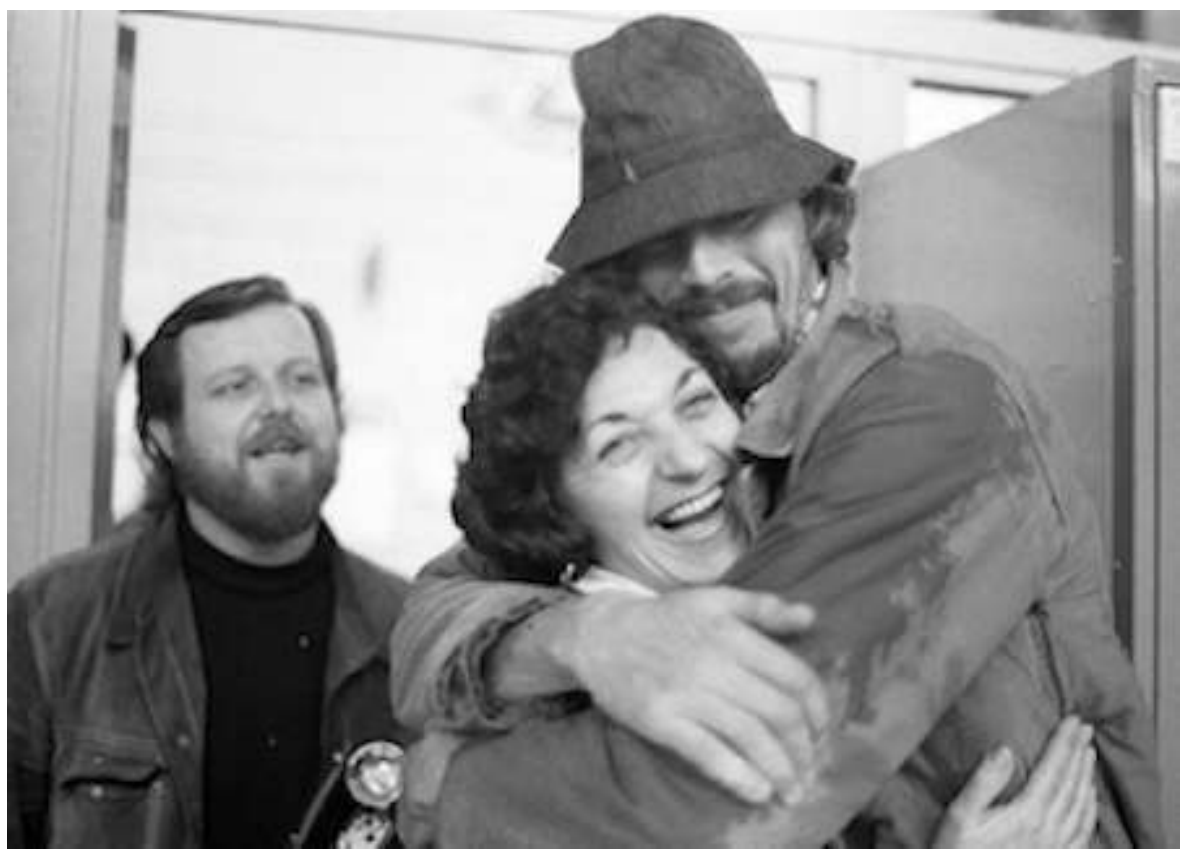

« Decoys », Rita Kaplowitz, non datée, par Jane Hoffer

(On the Beat, NYHS, Box 1, Folder 10). ( Jane Hoffer

Ces divers instantanés de vie professionnelle, qui vont de la complicité à la simple coexistence des corps dans un même lieu, donnent à voir une insertion des femmes bien plus profonde et complète que les reportages de Spring 3100. De fait, si la proximité des corps est parfois représentée dans les colonnes de la revue, elle ne va jamais jusqu'à 
l'évocation de la complicité amicale ou physique (Rita Kaplowitz visible sur la photographie $n^{\circ} 33$ évoque, dans un entretien avec la photographe, des situations de flirt assumées). Il s'agit probablement à la fois de ne pas amoindrir la dignité de l'institution et de ne pas provoquer l'hostilité des femmes de policiers qui peuvent lire la revue. Cette hostilité, attestée par les témoignages de nombreuses policières, fut même exprimée en 1974 lors d'une manifestation organisée pour dénoncer la présence des policières dans les voitures de patrouille ${ }^{22}$.

Les réactions de rejet dans le travail quotidien de la part de certains collègues masculins apparaissent cependant peu, que ce soit dans Spring 3100 ou dans le travail de Jane Hoffer. Leur inadéquation avec l'idéologie unitaire de l'institution les rend peu admissibles dans la revue officielle. Néanmoins, ces réactions sont évoquées par certaines des policières interrogées par la photographe. C'est probablement une des limites de l'outil photographique qui explique que la photographe ait choisi d'inclure dans son catalogue On the Beat une transcription partielle des entretiens (une autre partie des transcriptions est conservée à la New York Historical Society). Cependant, les photographies montrent à quel point la proximité entre les corps met le travail des policières directement sous l'œil de leurs collègues masculins. C'est une conséquence de la disparition d'un corps spécifique de policières et de l'intégration accentuée de celle-ci dans le département. Toutes les policières interrogées ou presque témoignent, d'ailleurs, du poids psychologique que cette pression exerce et de la peur de mal faire son travail qui s'en suit ${ }^{23}$.

Il est, toutefois, un espace révélé par le travail photographique de Jane Hoffer qui échappe au regard masculin et qui tranche plus significativement encore avec la production visuelle institutionnelle de Spring 3100 : les vestiaires des policières.

Photographie $n^{\circ} 34$.

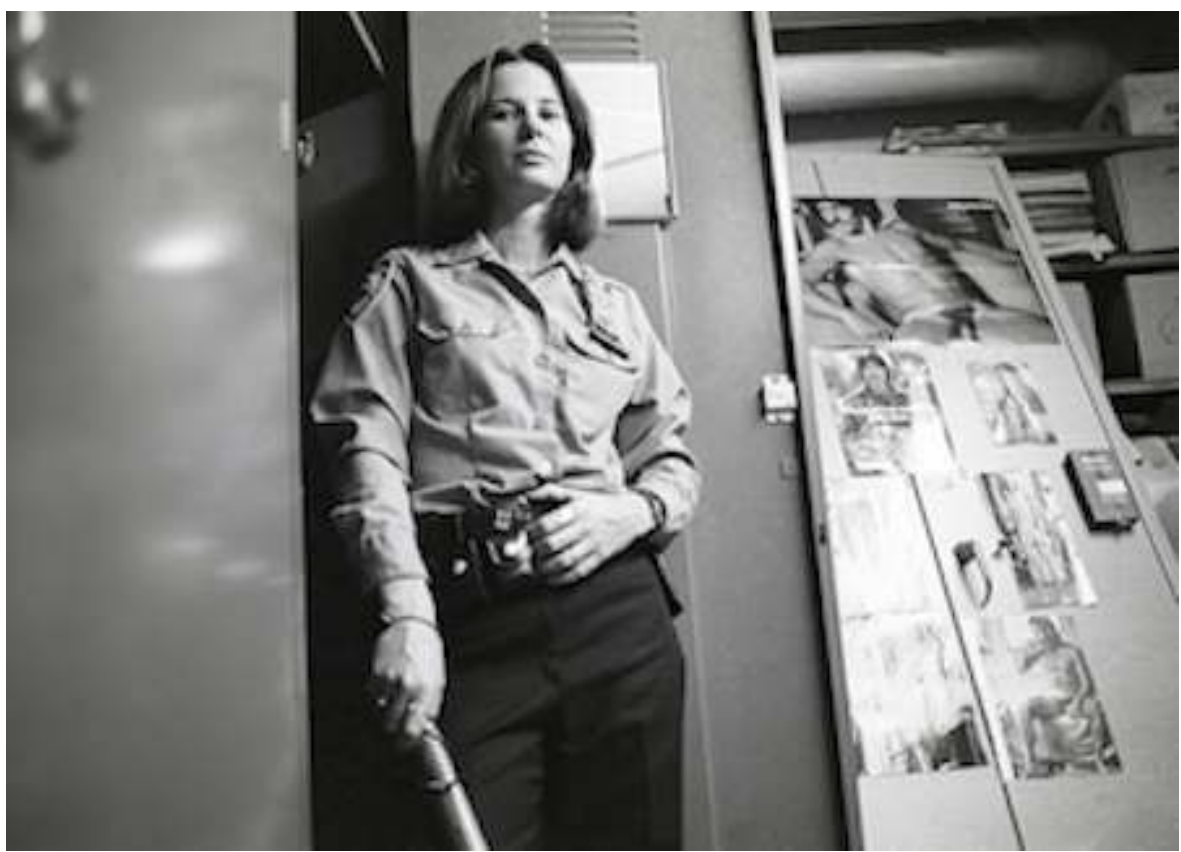

Agent Val Doran, par Jane Hoffer, non datée

(On the Beat, NYHS, Box 1, Folder 30). (c) Jane Hoffer 
Derrière le casier de la policière, on aperçoit la porte d'un autre casier recouverte de photographies d'hommes nus. La photographie offre au lecteur de Spring 3100 un écho, certes plus crû, aux dessins de Malone et Sherry. Mais elle opère un renversement de la charge humoristique et sexuelle, d'autant qu'on devine la matraque au bout de la main de la policière. Elle montre un autre univers quotidien, professionnel et sexué, à la polarité renversée où la sexualisation des corps est également le fait des femmes, sans que l'on puisse, cependant, vérifier si cela s'étend - comme le suggéraient Malone et Sherry pour les policiers - aux corps si proches de leurs collègues masculins. Dans ce cas cependant, la portée esthétique de la photographie semble supérieure à sa valeur indiciaire. Selon Jane Hoffer, la situation représentée constituait un cas peu représentatif des normes de genre au sein du groupe professionnel. La policière en question, trop franc-tireuse, ne serait d'ailleurs pas restée longtemps au sein du NYPD ${ }^{24}$.

Dans sa radicalité même, l'image de l'agent Val Doran montre toutefois que l'expérience des policières au travail (l'existence d'un vestiaire réservé qui peut être visuellement habillé, les contacts quotidiens avec les hommes dans un univers sexué) façonne l'expression de leur féminité, tout autant que leur identité sexuelle modèle leur environnement professionnel. Le détour par le travail d'une femme photographe et extérieure à l'institution et situant résolument son point de vue du côté des femmes, nous conduit dès lors à tenter de réévaluer de façon rétrospective la contribution des femmes à l'univers visuel majoritairement masculin de la revue Spring 3100.

\subsection{Policières d'abord ? Contribution des policières à l'univers visuel de Spring 3100}

68 Du fait de leur très faible rôle éditorial dans Spring 3100, les policières décident assez peu du sort des images dans la revue. Au mieux sont-elles des collaboratrices régulières livrant des reportages écrits sur les regroupements spécifiquement féminins du NYPD (la section de la police féminine, l'association des policières). Cela ne signifie toutefois pas que les policières ne contribuent visuellement en rien à la revue et que celle-ci ne nous renseigne en rien sur leur expérience professionnelle.

Spring 3100 illustre la profondeur de la relation des policières à l'institution. Diverses étapes de la carrière des policières sont ainsi documentées. L'entrée dans la police et l'accession à des responsabilités importantes font, comme on l'a vu, partie des contenus ordinaires de la revue. Les anniversaires de promotion sont plus irrégulièrement couverts. Ici la promotion 1949 de policières fête ses dix, puis ses vingt ans de présence dans le NYPD : 
Photographies $n^{\circ} 35$ et $n^{\circ} 36$

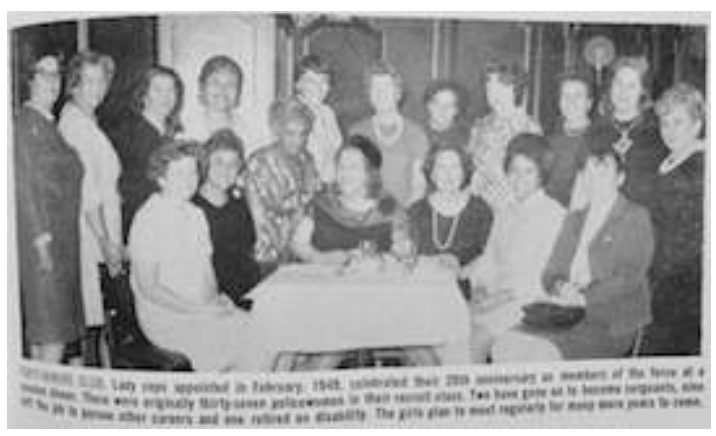

Photographie $n^{\circ} 36$.

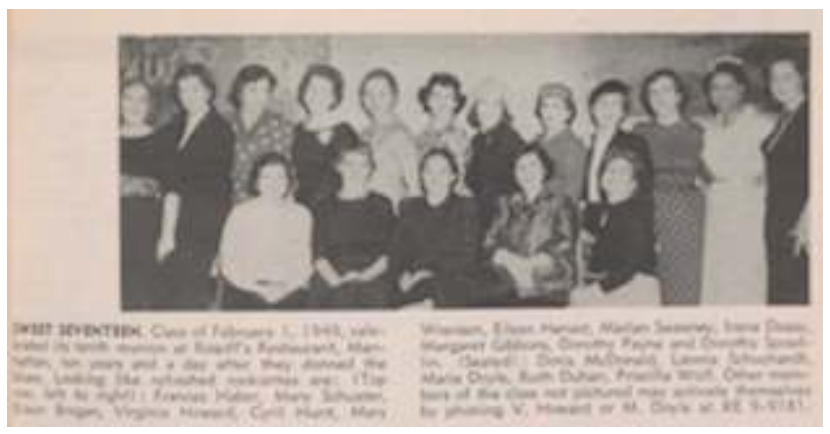

Spring 3100, mars 1959, p. 35 et septembre 1969, p. 25

Ces images servent la communication de la police qui aime à se définir comme une grande famille. Mais elles indiquent également l'investissement de ses différents membres dans l'institution. La sortie de la police, qui constitue par définition un événement plus personnel qu'institutionnel, fait ainsi également l'objet de reportages : 
Photographies $n^{\circ} 36$ et $n^{\circ} 37$.

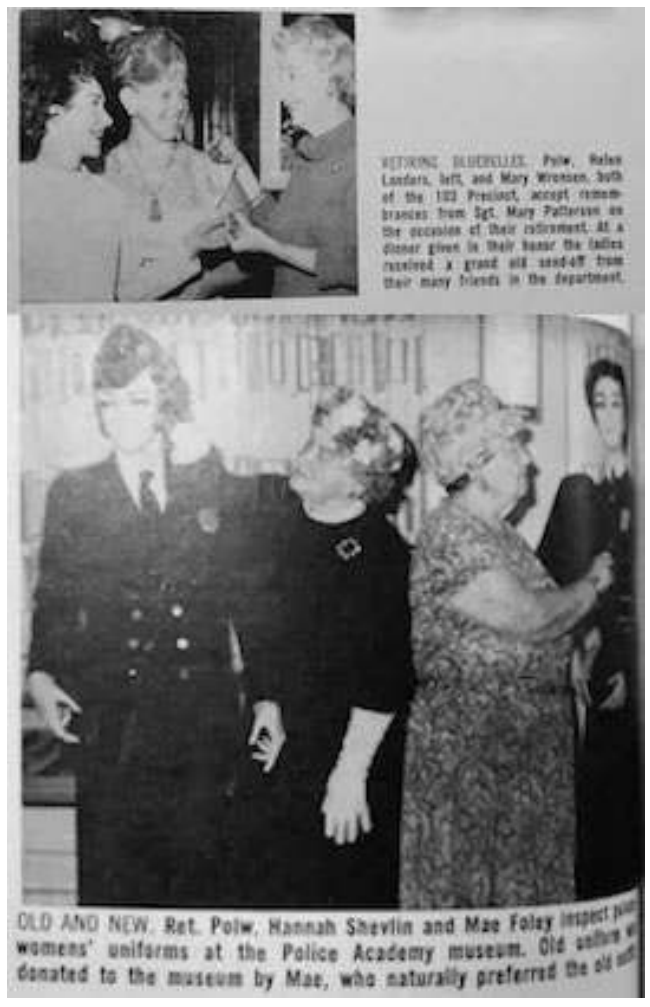

Spring 3100, mai 1969, p. 17 et septembre 1967, p. 20

Photographies $n^{\circ} 38$ et $n^{\circ} 39$.

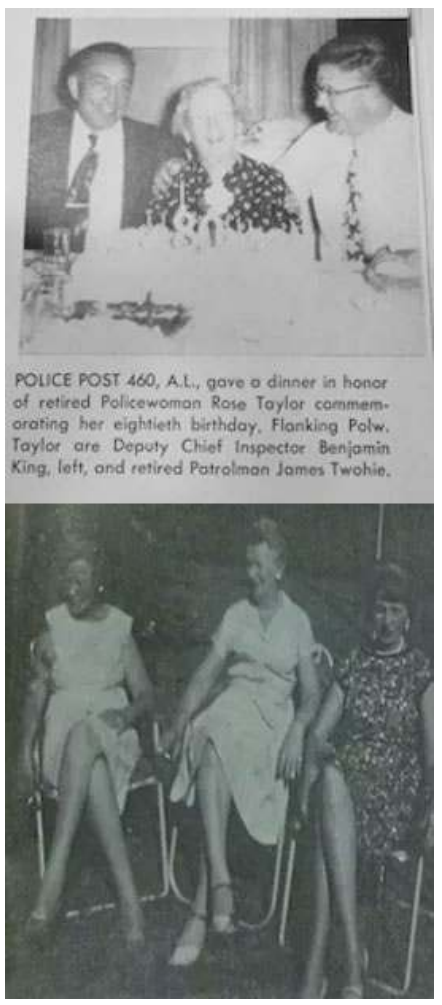

Spring 3100, novembre 1954, p. 23, et décembre 1966, p. 17 
71 Par leur distance croissante avec l'institution, ces quatre photographies témoignent de la solidité des liens de certaines policières avec le groupe professionnel. La photographie $n^{\circ} 36$ signale l'organisation d'une petite cérémonie à l'occasion du départ à la retraite de deux policières. Un événement banal, commun à de très nombreuses professions : un dîner avec remise de cadeaux. La photographie $n^{\circ} 37$ rend hommage à des policières retraitées venues inspecter divers uniformes dans le musée installé au sein de l'école de police (l'une d'entre elles n'est autre que celle ayant fait don des uniformes au musée). Un commissariat fête le quatre-vingtième anniversaire d'une policière depuis longtemps à la retraite $\left(n^{\circ} 38\right)$. Enfin, des policières retraitées envoient des photographies de leurs vacances $\left(n^{\circ} 39\right)$.

Le dernier exemple atteste que ce sont parfois les policières - ou anciennes policières qui alimentent la revue en images. Elément d'illustration récurrent de la revue professionnelle qu'est Spring 3100, les photographies de vacances ajoutent une dimension intime et rompent le caractère formel et répétitif des reportages sur les différentes unités du département. L'abolition temporaire de la séparation entre travail et hors-travail, sans être propre au groupe policier, illustre et renforce le sentiment d'appartenance à l'organisation :

Photographies $n^{\circ} 40$ et $n^{\circ} 41$.

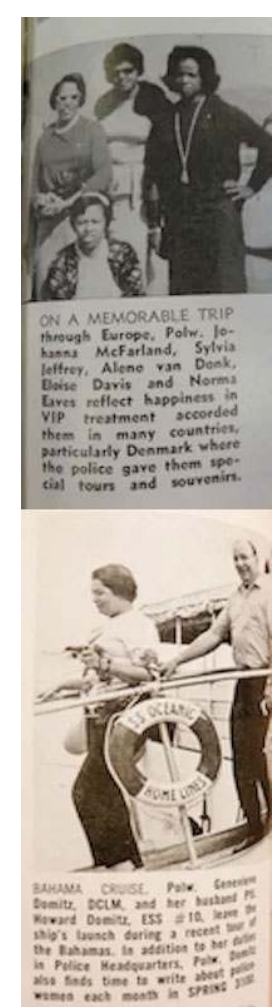

Spring 3100, juin 1963, p. 43 et décembre 1969, p. 46

Certains de ses voyages peuvent avoir une coloration professionnelle, comme celui de ces policières en Europe (photographie $n^{\circ} 40$ ) où elles ont été accueillies par des forces de police européennes - même si pour ces policières noires, ce voyage, en un moment de forte mobilisation pour les droits civiques, a sans doute eu des répercussions personnelles. Mais d'autres voyages (photographie $\mathrm{n}^{\circ} 41$ ) apparaissent purement privés, comme le voyage aux Bahamas de la policière Genevieve Domitz. Contrairement 
à beaucoup d'autres mises en scène de clichés de couples policiers en vacances, c'est bien sur la policière que l'accent est mis, sans doute parce que celle-ci est une contributrice de la revue (elle couvre la police féminine).

Enfin, les photographies signifient à quel point être membre du NYPD est une affaire familiale :

\section{Photographie $n^{\circ} 42$.}

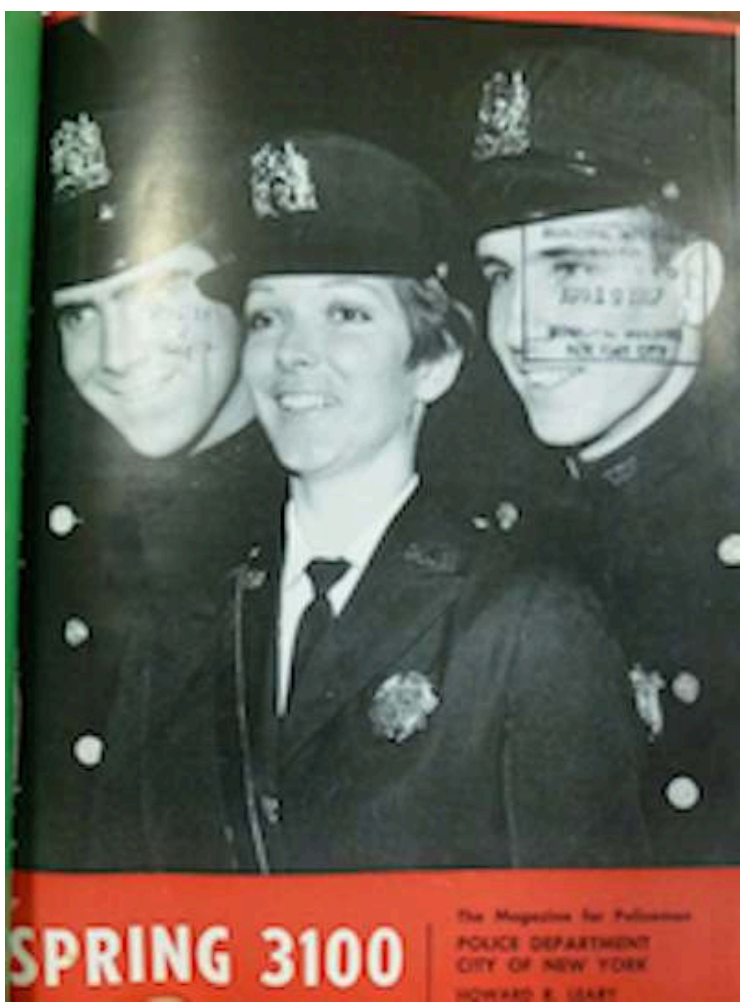

Trois membres de la famille Naughton font leur entrée ensemble dans le département Spring 3100, avril 1967, couverture 
Photographies $n^{\circ} 43$.

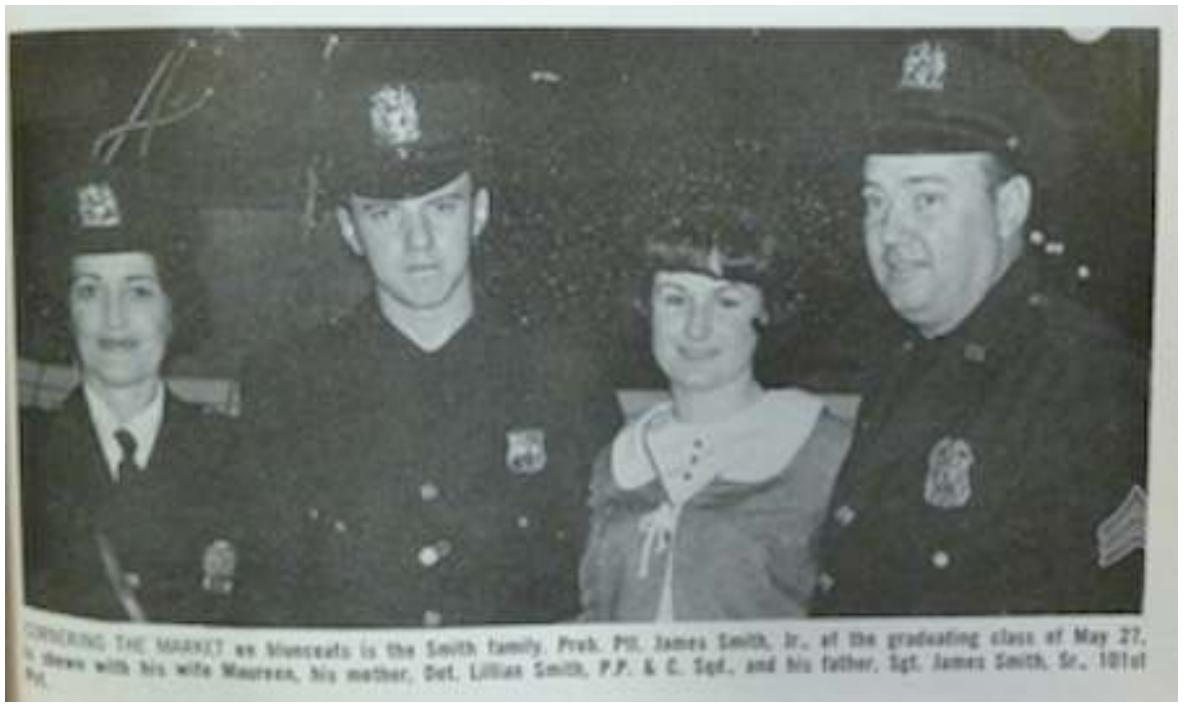

Spring 3100, juillet-août 1966, p. 7

Photographie $n^{\circ} 44$.

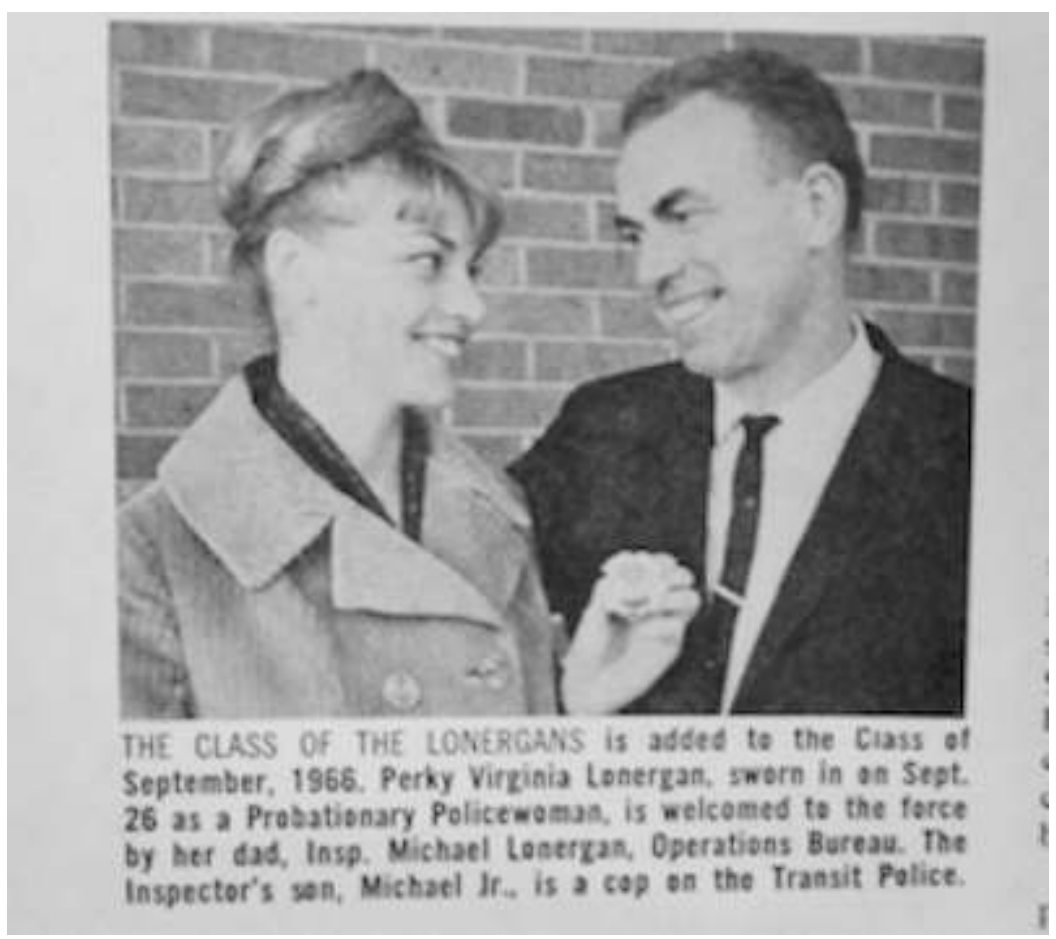

Spring 3100, novembre 1966, p. 6

Presque tous les liens familiaux entre membres du département sont représentés ici : frères/sœur $\left(n^{\circ} 42\right)$, père/fille $\left(n^{\circ} 44\right)$, mère/fils $\left(n^{\circ} 43\right)$, mari/femme $\left(n^{\circ} 43\right)$. Les mariages des membres du département sont régulièrement annoncés et illustrés dans la revue : 


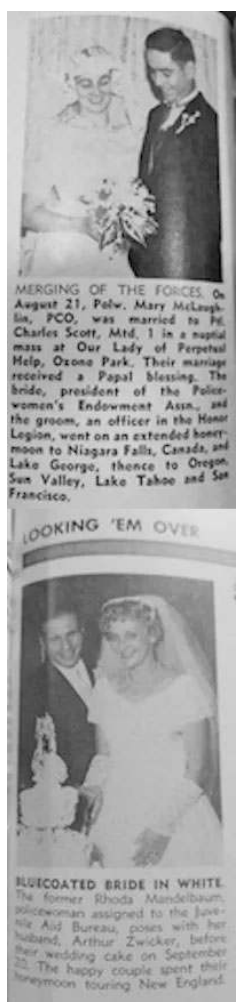

Spring 3100, décembre 1965, p. 46, novembre 1959, p. 43

76 La première photographie montre une union entre un policier et une policière, ce qui autorise différents jeux de mots célébrant l'union des polices. Mais la troisième montre le mariage entre une policière et un civil : c'est donc la mariée qui est célébrée et qui est probablement à l'origine de l'envoi de la photographie.

Ces divers documents soulignent la puissance intégratrice d'une organisation aussi large que le NYPD. Loin d'être simplement une organisation bureaucratique, c'est un puissant lieu de socialisation qui modèle la vie individuelle et familiale de ses membres, influant sur leurs choix matrimoniaux ou sur les choix professionnels de leurs enfants. Si les femmes policières restent longtemps des femmes aux yeux de l'institution, elles sont indéniablement policières à leurs propres yeux, comme l'exprime Patricia Thornton, une des premières policières à patrouiller dans les rues de New York : «Je ne me dis pas vraiment que je suis une femme quand je suis en service. On réagit d'abord en flic, puis seulement ensuite en femme $»^{25}$. Pourtant, quand la promotion 1966 fête ses retrouvailles en 1970, ce sont certaines policières elles-mêmes qui, par leur pose, mettent en valeur leur identité physique de femmes et notamment leurs jambes : 


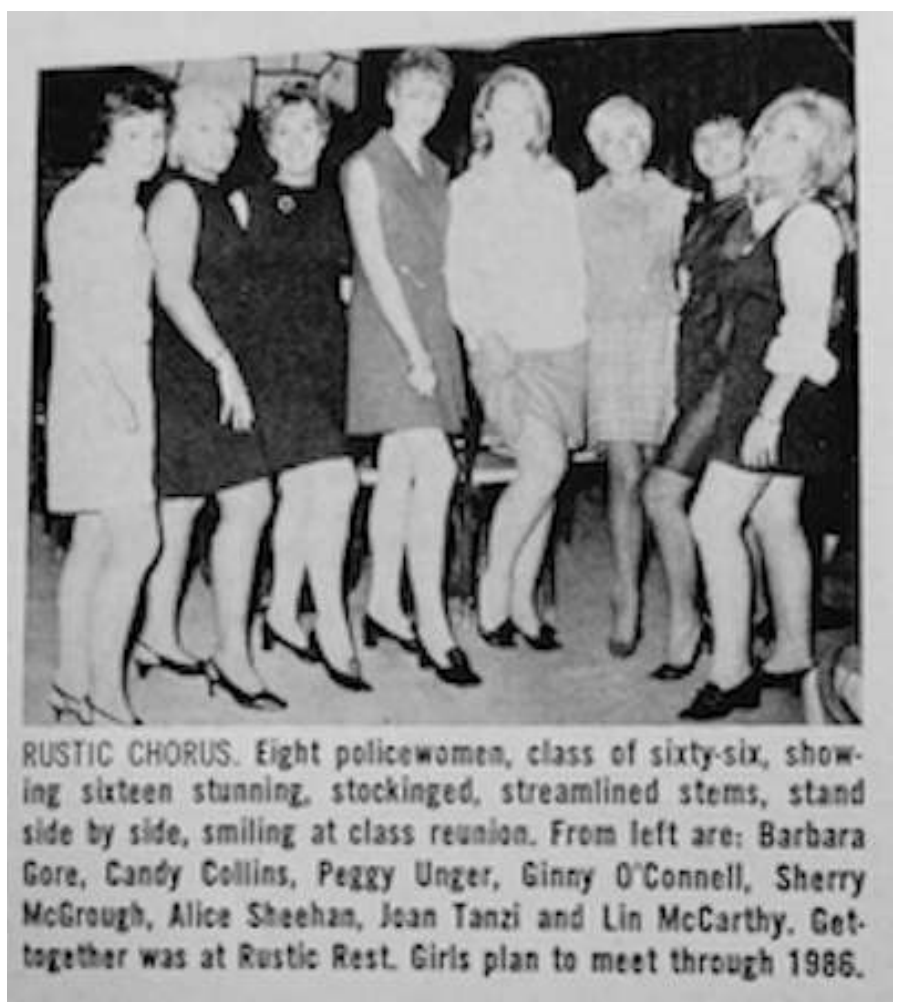

Spring 3700, février 1970, p. 40

78 La pose semble appeler le commentaire (huit femmes, seize magnifiques gambettes !). Il ne s'agit cependant pas ici de produire un spectacle comme lors du gala annuel de la police féminine. Est-ce une façon d'intérioriser les normes en vigueur dans le département? Souligner son identité distinctive de femme peut, en effet, accroître ses chances d'accéder à des fonctions d'enquêtrices. Celles-ci sont encore peu nombreuses et correspondent donc à un type ou emploi susceptible d'être recherché. Ou alors est-ce une convention d'évocation d'un groupe féminin? Dans tous les cas, cela indique que travailler comme policière au sein du département peut se décliner de façons diverses et donner lieu à des archives visuelles variées.

\section{Conclusion}

La production d'images des policières au travail dans une institution aussi symboliquement masculine qu'a été le NYPD est historiquement inséparable du débat sur la présence des femmes dans l'institution. Aussi, notre réflexion sur les archives visuelles a-t-elle consisté à prendre en compte de façon systématique les conditions de production de ces images dans la revue du département afin d'évaluer leur potentiel d'archives visuelles pour l'historien ou l'historienne. À la fois institutionnelle et masculine, codifiée et relativement libre dans son ton, Spring 3100 sert ainsi longtemps de vecteur à la diffusion des normes masculines qui définissent la profession et soudent le groupe. Elle réserve dès lors un espace et un registre réduits aux policières, qui s'élargit cependant à la faveur la féminisation accrue de la profession à partir des années 1960. Par sa relative liberté de ton et par son souci d'attirer des lecteurs peu férus de lectures fastidieuses, la revue propose un langage visuel riche, humoristique et 
varié, offrant une fenêtre sur la culture formelle et informelle de l'institution. Elle renseigne ainsi sur les perceptions, souvent sexistes, des policiers masculins face aux transformations en cours et, par ricochet, sur les multiples façons pour les femmes policières de New York de faire corps avec une organisation professionnelle les traitant inégalement. L'accession à l'égalité hommes-femmes au sein du département aurait pu se traduire par l'accession à une forme d'égalité dans la représentation, y compris dans les formes d'expression ludique et humoristique. Cependant, les difficultés de la revue à maintenir son lectorat dans les années 1970 et son institutionnalisation accrue accentuent le formalisme de son écriture comme de ses contenus, diminuant d'autant son potentiel documentaire à un moment où les images de femmes policières deviennent plus familières au grand public, ne serait-ce qu'à travers la diffusion de la série télévisée Cagney \& Lacey, mettant en scène les deux détectives new-yorkaises éponymes, sur les écrans américains à partir de 1982.

\section{BIBLIOGRAPHIE}

Assegond C. (2012), « Les débuts de la photographie du travail usinier : production, représentations, usages (1870-1915) », in J-P. Géhin et H. Stevens (dir.), Images du travail, travail des images, Rennes, PUR, p. 87-100.

Brodeur J-P. (2003), Les Visages de la police, pratiques et perceptions, Montréal, PUM.

Burke K. (2006), Detective: The Inspirational Story of the Trailblazing Woman Cop Who Wouldn't Quit, New York, Scribner.

Darien A. T. (2013), Becoming New York's Finest : Race, Gender, and the Integration of the NYPD, 1935-1980, Palgrave, McMillan, New York.

Lannoy P. (2012), « Montrer la nation au travail dans l'industrie automobile durant l'entre-deuxcrises (1929-1973) », in Jean-Paul Géhin et Hélène Stevens (dir.), Images du travail, travail des images, Rennes, PUR, p. 101-115.

Melchionne T. M. (1962), « Policewomen : their introduction in the police department of the City of New York (A Study of Organizational Response to Innovation) », M.P.A. Thesis, Bernard M. Baruch College, City University of New York.

Palczewski C. H. (2005), « The Male Madonna and the Feminine Uncle Sam : Visual Argument, Icons, and Ideographs in 1909 Anti-Woman Suffrage Postcards », The Quarterly Journal of Speech, $91: 4$, p. 365-394.

Philippe Y. (2011), «Community Mothers or Impromptu Actresses? The Multifaceted Experience of Women in the New York Police Department (1900-1941) », Law Crime and History, vol. 1 issue 1, p. 35-61.

Philippe, Y. (2018), « Femmes et hommes en métier d'hommes : répertoires professionnels du masculin et du féminin dans le New York Police Department (NYPD) dans la première moitié du XXe siècle ", in Divay S. et L. Sibaud (dir.), Variations sur le thème du genre dans les groupes professionnels, Toulouse, Octarès, p. 23-49. 
Pruvost G. (2008), De la « sergote » à la femme flic : une autre histoire de l'institution policière (1935-2005), Paris, La Découverte.

Rennes J. (2013a), « Genre, travail et culture visuelle » in Maruani M., Genre et travail dans le monde, Paris, La Découverte.

Rennes J. (2013b), Femmes en métiers d'hommes. Cartes postales 1890-1930, Saint-Pourçain-sur-Sioule, Éditions Bleu autour.

Schulz D. M. (1995), From Social Worker to Crimefighter : Women in US Municipal Policing, Praeger, Westpoint, Connecticut.

Shpritzer F. (1959), «A Case for the Promotion of Policewomen in the City of New York

», The Journal of Criminal Law, Criminology, and Police Science, vol. 50, $\mathrm{n}^{\circ}$ 4, Novembre - Décembre, p. 415-419.

Sullivan M. (1938), My Double Life : The Story of a New York Policewoman, New York, Farrar \& Rinehart.

Thale C. P. (1995), « Civilizing New York City : Police Patrol, 1880-1935 », PhD, University of Chicago.

\section{NOTES}

1. Pour un point de vue sur la relative insignifiance de la revue Spring 3100, voir Thale, 1995, p. 908-909.

2. Le NYPD est dirigé par un haut-commissaire à la police ("Police Commissioner» en anglaisaméricain), nommé par le maire de New York et entouré d'adjoints (« Deputy Commissioners ») qui dirigent les diverses unités de l'organisation.

3. The New York Times, 7 septembre 1961, p. 37, 18 novembre 1961, p. 12 et 9 décembre 1961, p. 56 ; 28 novembre 1962, p. 41 ; 7 juin 1963, p. 22, 2 octobre 1963, p. 40, 16 novembre 1963, p. 24, 11 avril 1964, p. 8 et 12 avril 1964, p. 57.

4. Spring 3100, Avril 1965, p. 4.

5. The New York Times, 9 décembre 1961, p. 56 et 28 novembre 1962, p. 19.

6. La légende accompagnant la photographie est la suivante : «Policewoman Mary Culkin, left and the man she nabbed on Nov. 20 as he was found lurking in her apartment house. Just out of Police Academy, Polw. Culkin was assigned to Detective Division for her commendable work. Mirror Photos " (Spring 3100, janvier 1960, p. 8).

7. La légende de la photographie $n^{\circ} 16$ indiquait: « Des 651 recrues qui sont sorties diplômées de l'école de police le 4 mars, les quatre jolies policières ci-dessus sont celles qui accrochaient le plus le regard » (Spring 3100, Avril 1957, 4).

8. Spring 3100, Février 1950, 23.

9. Ces manifestations sont organisées par une association de policiers majoritairement noirs. L'unique policière blanche, par ailleurs mariée à un policier noir, est cependant la responsable de ces spectacles qui ont déjà fait l'objet d'illustrations similaires dans la revue.

10. Voir à ce sujet, le témoignage de M. Sulivan (1938) et le reportage photographique de J. Hoffer plus bas.

11. Dans le NYPD, l'accès aux grades supérieurs (sergent, lieutenant, capitaine) n'est ouvert qu'à des policiers ayant commencé leur carrière au bas de la hiérarchie comme simples agents. Il n'y a pas d'accès direct par la voie d'un concours spécifique, comme celui de commissaire en France. L'expérience de la patrouille (forcément marquante car elle se fait alors pour la majorité des 
agents en solitaire et à pied) tout comme la supervision exercée par les supérieurs hiérarchiques directs que sont les sergents sont dès lors des thèmes familiers à l'ensemble de l'effectif policier. 12. On retrouve ce répertoire de l'expression masculine dans les dessins de Dan Malone analysés plus bas. Sur les représentations d'une masculinité polymorphe, voir Philippe, 2018.

13. Le dessin est suffisamment ritualisé pour être repris de façon très similaire trois ans plus tard en variant seulement la physionomie de la policière.

14. The New York Times, 11 avril 1964, 8 et 12 avril 1964, 57.

15. The New York Times, 13 mars 1965, 28. Dans l'article qu'elle consacrait à la question en 1959, Shpritzer adoptait une vision moins stratégique, plus nuancée et sans doute plus réaliste. Tout en reconnaissant qu'il serait administrativement malavisé de nommer des femmes sergents dans des commissariats pour superviser des hommes en patrouille, Shpritzer convoquait des exemples de forces de police où des femmes se trouvaient en position de commander des effectifs mixtes (Londres, Detroit). Elle faisait enfin la liste de toutes les unités où des femmes pourraient exercer leur autorité de sergents : sections de la jeunesse, des personnes disparues, des pickpockets. Ces unités étant mixtes, shpritzer ouvrait ainsi implicitement la voie à des situation d'autorité féminine sur des policiers masculins (Shpritzer, 1959, 415-419).

16. "Quiet, junior, your mother will be with you as soon as she finishes turning out the platoon».

17. "Why did I ever encourage her to take the lieutenant's test? "

18. Pour des réactions plus développées de policiers masculins opposés au changement et d'autres exemples de « cop captions », voir Darien, 2013, 118-122.

19. C. H. Palczewski montre comment les images peuvent à la fois refléter des arguments déjà constitués et en évoquer d'autres moins dicibles (2005, 365-394).

20. Une expérimentation très partielle consistant à affecter les femmes policières à des fonctions policières ordinaires mais à l'exception de la patrouille a été lancée dans le NYPD en 1967 (Spring 3100, septembre 1967, 48). Elle est étendue en 1968 et conduit à l'abolition du Bureau de la police féminine sans pour autant aboutir à une égalité des affectations, voir A. T. Darien $(2013,233$, note 36).

21. Jane Hoffer, On the Beat 1975-79, Foreword, in Jane Hoffer, On the Beat Photograph Collection, PR 312, Department of Prints, Photographs, and Architectural Collections, The New-York Historical Society, Box 1, Folder 40. Les photographies furent exposées à la Soho Photo Gallery en 1981, puis au John Jay College of Criminal Justice en 1989 et enfin au New York City Police Museum en 2011.

22. Rita Kaplowitz in Jane Hoffer, On the Beat (NYHS, Box 1, Folder 39 « Interviews ») ; Spring 3100, Mai 1969, 48 ; New York Times, 21 juin 1974, 41 pour la manifestation de femmes de policiers.

23. Pour une discussion approfondie des différentes attitudes adoptées par les policières pour faire face à la pression, voir A. Darien, 2013, 122-124.

24. Propos rapportés à l'auteur par Jane Hoffer dans une conversation par mail.

25. Propos cités dans The New York Times, 12 août 1973, p. 53.

\section{RÉSUMÉS}

Les images d'une revue institutionnelle peuvent-elles constituer des archives visuelles du travail policier féminin? À travers l'étude de la revue du New York Police Department, Spring 3100 et une comparaison avec le travail de la photographe Jane Hoffer, cet article interroge l'existence d'une iconographie professionnelle et son utilisation par la recherche pour suivre la féminisation d'un 
groupe professionnel, les réactions du groupe masculin à ces transformations et l'insertion des femmes dans l'institution.

Can images of an institutional magazine be used as visual archives of women's police work? Through the study of Spring 3100, the magazine of the New York Police Department, and a comparison with the work of photographer Jane Hoffer, this article explores an occupational iconography and reflects on its use by researchers to monitor the feminization of a professional group, the reactions of male workers to this process and the negotiation by policewomen of their own occupational identity.

\section{INDEX}

Mots-clés : féminisation, travail, policières, policiers, photographie, dessins humoristiques

Keywords : feminization, work, policewomen, policemen, photography, cartoons

\section{AUTEUR}

\section{YANN PHILIPPE}

Maître de conférences en histoire et civilisation américaines à l'université de Reims Champagne Ardenne et membre du Centre d'Études Nord-Américaines (MA-EHESS). Il a soutenu en 2006 une thèse intitulée « Mais que fait la police ? Réformes policières et lutte contre la criminalité à New York au début du XXe siècle (1906-1918) ». Ses travaux visent à interroger la police comme objet total d'enquête, dans ses multiples dimensions politique, judiciaire, sociale et culturelle, sur la société américaine. Il travaille actuellement sur la construction, au XXe siècle, à l'échelle des États-Unis d'un fédéralisme policier associant les diverses forces de police du pays aux différents échelons de l'État. 